\title{
WAGE DYNAMICS ALONG THE LIFE-CYCLE OF MANUFACTURING PLANTS
}

by

\author{
Emin Dinlersoz * \\ U.S. Bureau of the Census \\ Henry Hyatt * \\ U.S. Bureau of the Census \\ and \\ Sang Nguyen * \\ U.S. Bureau of the Census
}

CES 11-24

August, 2011

The research program of the Center for Economic Studies (CES) produces a wide range of economic analyses to improve the statistical programs of the U.S. Census Bureau. Many of these analyses take the form of CES research papers. The papers have not undergone the review accorded Census Bureau publications and no endorsement should be inferred. Any opinions and conclusions expressed herein are those of the author(s) and do not necessarily represent the views of the U.S. Census Bureau. All results have been reviewed to ensure that no confidential information is disclosed. Republication in whole or part must be cleared with the authors.

To obtain information about the series, see www.census.gov/ces or contact Cheryl Grim, Editor, Discussion Papers, U.S. Census Bureau, Center for Economic Studies 2K130B, 4600 Silver Hill Road, Washington, DC 20233, CES.Papers.List@census.gov. 


\begin{abstract}
This paper explores the evolution of wages along the life-cycle of U.S. manufacturing plants. Real wages start out low for new plants, and increase along with productivity as plants survive and age. As plants experience productivity decline and approach exit, real wages fall. However, for failing plants real wages do not fall as quickly as they rise in the case of new entrants. These empirical regularities are captured in a dynamic model of labor quality and quantity choice by plants subject to adjustment costs in wages and employment. The model's parameters are estimated to assess the magnitude of adjustment costs and the degree of asymmetry in the cost of upward versus downward adjustments.
\end{abstract}

* The authors are with the Center for Economic Studies, U.S. Census Bureau, 4600 Silver Hill Road, Suitland, MD 20746. Any opinions and conclusions expressed herein are those of the authors and do not necessarily represent the views of the U.S. Census Bureau. All results have been reviewed to ensure that no confidential information is disclosed. 


\section{Introduction}

This paper provides evidence on the evolution of wages along the life-cycle of manufacturing plants using comprehensive data from U.S. Census Bureau's Census of Manufactures over the period 1963-1997. It first describes how the average wage paid by a plant changes as the plant enters an industry, grows, and ages, and as it approaches exit. It then builds and estimates a dynamic model of plant-level wage adjustment to account for the asymmetric pattern observed in the evolution of wages for growing versus declining plants.

The analysis is motivated by the evolution of key plant-level variables in the U.S. quinquennial Census of Manufactures (CM). The CM waves were linked at the plant level to form an unbalanced panel over the period 1963 through 1997. Plants are observed at most eight times, when they appear in all waves of the CM starting from 1963. Using a plant's deflated total revenue (total value of shipments), its deflated total wage bill, and its total employment, three ratios were constructed for each plant-CM wave observation: ${ }^{1}$ (a) average wage - the ratio of wage bill to employment, (b) labor productivity - the ratio of revenue to employment, and (c) the ratio of wage bill to revenue, equivalent to the ratio of (a) to (b). Each ratio was then regressed on lifecycle indicators - a set of dummy variables indicating the number of CM waves a plant has been observed prior to its exit and after its entry, up to five each. ${ }^{2}$ The omitted category contains the plants that are more than twenty years away from their entry or exit, and the plants for which entry or exit do not fall into the sample period. ${ }^{3}$ Each regression also includes dummies for 4-digit SIC industry - CM wave interactions, to control for industry and time effects. The coefficient estimates for the life-cycle indicators are in Figure 1.

First, consider the evolution of average wage in Figure 1a. New plants begin with an average wage roughly $\$ 2,700$ lower than that of the omitted category. It takes at least twenty years for the gap to drop below $\$ 300$. Average wage starts to fall as a plant approaches exit. Plants twenty years away from exit have about $\$ 200$ lower average wage than the omitted category. This gap grows to $\$ 2,000$ by the time of exit. Average wage for plants in their last census before exit is about $\$ 700$ higher than that of entrants in their first census year. Wages tend to rise faster for

\footnotetext{
${ }^{1}$ Both wages and revenue are expressed in 1987 dollars. Wages were deflated by the Consumer Price Index (CPI) from the Bureau of Labor Statistics (BLS), and revenue was deflated using industry-level deflators from the NBER-CES Manufacturing Industry Database ( http://www.nber.org/data/nbprod2005.html).

${ }^{2}$ Entry and exit events are defined as the first observation of a plant in an economic census and the last observation, respectively. The exact entry and exit dates are not observed, and may fall in between two census years.

${ }^{3}$ These plants are those which enter before $1963 \mathrm{CM}$, and those that are still in operation as of $1997 \mathrm{CM}$.
} 
surviving entrants than they fall for plants that approach exit, as indicated by the slopes of the two average wage profiles.

Next, turn to the evolution of labor productivity in Figure 1b. Compared to the omitted group, new plants start off with approximately $\$ 5,700$ productivity disadvantage that diminishes over time. However, failing plants exhibit a much larger productivity disadvantage. Plants on the verge of exit have about $\$ 10,000$ lower productivity. Even as early as ten years prior to exit, they have around $\$ 4,000$ lower productivity. Labor productivity tends to fall faster for plants nearing exit than it rises for aging entrants.

The findings in Figures 1a-b together suggest the evolution of the ratio of a plant's wage bill to its revenue, or equivalently, the percent of a worker's productivity provided to the worker in the form of wages. The estimated life-cycle pattern for this ratio is shown in Figure 1c. New plants spend a lower fraction of their revenue on wage bill compared to the omitted category, although this wage advantage largely disappears over the next fifteen years for surviving plants. Plants approaching exit, however, exhibit a small but statistically significant increase in this ratio. During their last three censuses, failing plants on average spend a higher fraction of their revenue on wages compared to the omitted category.

Figure 1 reveals that the evolution of average wages tends to roughly mimic the evolution of labor productivity at the plant level. New plants have increasingly higher average wage as they age and their labor productivity improves. Failing plants have both lower average wage and productivity as they approach exit. Yet, there is a fundamental asymmetry: wages do not fall as fast as labor productivity does for plants approaching exit, but they rise faster than labor productivity for new plants that survive and age. The model in this paper considers the role of adjustment costs associated with wages as a potential explanation for this observed asymmetry.

The connection between firm tenure and wages arises for several reasons. Older firms may have higher wages because their workers tend to be more experienced, and have more human capital and better skills. Established firms with higher survival likelihood are more likely to honor long-term wage contracts, which induce higher worker effort and lead to higher wages. On the other hand, young firms that face significantly lower probability of survival may offer higher or lower wages, depending on whether they compensate their workers for the shorter tenure prospects they face, or promise a reward in the form of equity if the firm is successful. Wages deemed fair by workers can be higher in firms that are actually profitable enough to offer such wages. For instance, models of industry dynamics with persistent firm-level productivity, such as that of Jovanovic (1982), imply that established firms can afford higher wages because of their higher productivity - equivalent to 
profitability in some models. ${ }^{4}$

Using survey data on employees, Brown and Medoff (2003) find that older firms pay higher wages, but this wage premium disappears after controlling for worker characteristics. Older firms also offer steeper wage-tenure profiles. However, their analysis is based on a relatively small number of workers, and highly established firms with an average age of forty years. ${ }^{5}$ Kölling, Schnabel and Wagner (2002) largely confirm Brown and Medoff's (2003) findings using a larger dataset that links establishments to workers in Germany. These studies do not track firms or plants over time, and do not explicitly consider the dynamics of wages along the firm life-cycle. While age measures a firm's distance from entry, it does not contain information on its distance to exit, and cannot properly account for where a firm stands in its life-cycle. The samples used in these previous studies also do not adequately represent the age distribution of firms, especially young ones, which constitute a large fraction of firm population. This paper uses the entire population of U.S. manufacturing plants. It characterizes the evolution of wages not only for established plants, but also for those near entry and exit points. The knowledge of entry and exit episodes and the ability to track plants over time allow for a more complete picture of wage dynamics.

Given that productivity dynamics is a dominant source of firm dynamics, it is also important to understand how changes in productivity are reflected in wages. The model in this paper makes this connection explicit. ${ }^{6}$ The model considers a plant's adjustment of the quality of its labor force as one of the main drivers of changes in wages, consistent with the findings of Brown and Medoff (2003) and Kölling, Schnabel and Wagner (2002) that worker quality or skill account for a considerable portion of wage differential across plants of different ages. The analysis, however, does not attempt to disentangle the effect of worker versus plant characteristics on wage dynamics. The goal is not to explain away the differences in wages across plants at different stages of their lifecycles, but rather to explore the link between plant-level productivity dynamics and the evolution of wages along a plant's life-cycle.

The analysis also adds to the growing empirical literature on microeconomic foundations of

\footnotetext{
${ }^{4}$ The distinction between productivity and profitability was highlighted by Foster, Haltiwanger and Syverson (2008), who disentagle the price and output components of revenue in a set of narrowly defined, homogeneous goods manufacturing industries and show that younger plants have higher 'physical' productivity but tend to charge lower prices, implying lower profitability does not imply lower productivity.

${ }^{5}$ The sample consists of 1,067 workers, corresponding to at most as many firms. See Brown and Medoff (2003) for details.

${ }^{6}$ Some recent studies tie firm-level productivity movements to wage changes using reduced-form econometric models. See, e.g., Fuss and Wintr (2009).
} 
real wage movements. A large body of work has considered both nominal and real wage rigidity. ${ }^{7}$ In this paper, the focus is on adjustments in real wages. Forward-looking plants anticipate the effects of inflation on output and factor prices in making decisions. Nevertheless, the model and its estimation can readily accommodate nominal terms.

The specific mechanism that drives the evolution of wages in the model is a plant's adjustment of the quality of its labor force over time. Labor quality is a factor of production, in addition to the quantity of labor. While a plant takes as given the exogenous wage per unit of labor quality, it can alter the average quality of its labor force, and hence, its total wage bill and average wage. This mechanism is embedded into a model of plant dynamics driven by idiosyncratic shocks to plant profitability and common shocks to wage per unit of worker quality. Under certain specifications of production technology, when a plant's profitability increases, the plant desires to increase both its employment and average quality of its labor force, and a decline in profitability induces a downward pressure on both labor quality and employment. These implications emerge in the data studied here. Adjustments in wages, however, have costs associated with them. These costs may curtail the extent to which wages can be changed. In the model, plants make their labor quantity and quality choices considering the effects of these choices on current and future adjustment costs.

Adjustment costs associated with factors of production have been studied in the context of both firm-level and aggregate dynamics. ${ }^{8}$ These studies mainly consider adjustment costs for labor or capital, and usually ignore adjustment costs associated with factor prices, such as wages. Adjustment costs in wages may arise due to a variety of reasons. New plants experiencing favorable profitability shocks and fast growth may need to reorganize their labor force and adjust compensation to increase the average skill level and, therefore, output. Similarly, as a plant experiences persistent episodes of low profitability, it may be forced to shed some of its employees with high skill, but who may be non-essential for the main activity of the plant, and in some cases, it may even reduce compensation for some workers. There need not be a reduction in nominal compensation. For instance, if a plant freezes nominal wages for a while, real wages would fall under inflation. Similarly, some high skill workers may quit in anticipation of exit and the plant may then have to reorganize its labor force to maintain production. All of such actions and changes, however, require costly adjustment to wages. Changing the skill composition of a plant entails costly training and search for workers with desired skill levels. Unions can resist or prevent a reduction in average wage level, whether the reduction is direct through a cut in real wages and

\footnotetext{
${ }^{7}$ See, among others, Altonji and Devereux (1999), Bewley (1999), Hall (2005a,b), Blanchard and Gali (2007).

${ }^{8}$ See, among others, Cooper and Willis (2011), Cooper, Haltiwanger, and Willis (2010), Cooper and Haltiwanger (2006), Hall (2004), and Pfann and Palm (1993).
} 
benefits, or indirect through firing workers with a particular skill level. Exogenous shocks to wages can also force a plant to alter the wages paid to its workers. For instance, skilled workers can exercise their outside options if wages are not adjusted upwards properly when demand for skilled labor rises.

To uncover the underlying adjustment costs, as well as the shares of labor quantity and quality in the production function of a plant, the model's parameters are estimated using a generalized method of moments. The estimates reveal that labor quality, implicitly inferred from wages, is an important input to production. Furthermore, there are significant and asymmetric adjustment costs associated with wages. Adjustment costs in wages constitute around $1 \%$ of revenue at the median of the adjustment cost distribution across continuing plants. For continuing plants experiencing downward movement in average wage, the wage adjustment costs claim about $4 \%$ of revenue at the median. For continuing plants experiencing an increase in average wage, the adjustment costs make up $0.3 \%$ of revenue at the median. These shares are much higher when only the exiting plants are considered: $2 \%, 7.5 \%$, and $0.5 \%$, respectively. The share of adjustment costs in revenue is also higher for plants in the higher quartiles of the adjustment cost distribution. Furthermore, wage adjustment costs tend to decline as a percentage of revenue as new plants age, and increase as plants approach exit. A version of the model with both wage and employment adjustment costs is also estimated. Both margins of adjustment tend to be important.

The rest of the paper is organized as follows. Section 2 describes the data and presents some observations regarding the evolution of wages along a plant's life-cycle. Section 3 introduces the model. The estimation methodology based on the model is presented in Section 4. The estimation results are discussed in Section 5. Section 6 offers concluding remarks.

\section{The evolution of wages}

\subsection{Data}

The empirical work uses the Longitudinal Research Database (LRD), maintained at the Center for Economic Studies of the US Census Bureau. The LRD describes aspects of manufacturing plants' production. Output data include total value of shipments and value added. Data on inputs include information on capital, labor, energy, materials, and selected purchased services. The LRD also contains information on classification and identification of plants, such as plants' ownership, location, and industry, as well as various status codes that identify birth, death, and 
ownership changes. These identifying codes are used in developing the longitudinal plant linkages. ${ }^{9}$

The analysis focuses on a subset of the LRD that includes eight waves of Census of Manufactures (CM): 1963, 1967, 1972, 1977, 1982, 1987, 1992 and 1997. The number of plants in CM range from 305,691 in 1967 to 400,036 in 1997. Using permanent plant numbers in the CM, plants were linked from these CM's to form an unbalanced panel for the period 1963-1997. Plant entry, exit, and continuation were identified.

The key variables are revenue, employment, and average wage. A plant's revenue is its value of shipments deflated to 1987 dollars using 4-digit SIC level industry price deflators from NBERCES Manufacturing Industry Database based on 1987 SIC code definitions. Employment is a plant's total number of workers engaged in production and non-production activities. The wages of individual workers in a plant are not observed, only the total wage bill is available. To obtain average wage, a plant's total wages and salaries were deflated to 1987 dollars using CPI from Bureau of Labor Statistics and then divided by the plant's total employment. Wages do not include benefits. ${ }^{10}$ Labor productivity is defined as the ratio of a plant's revenue to its total employment. Finally, wage-bill-to-revenue ratio is a plant's total wage bill divided by its revenue.

\subsection{Main findings}

Underlying the evolutions of the three basic ratios described in Figure 1 is Table 1, which contains the OLS estimates from several specifications of the following regression

$$
Y_{i t}=\alpha+\sum_{\tau} \beta_{X}^{\tau} X_{i t}^{\tau}+\sum_{\tau} \beta_{E}^{\tau} E_{i t}^{\tau}+\boldsymbol{\beta}_{Z} \mathbf{Z}_{i t}+\beta_{I T} T_{t} I_{i}+\varepsilon_{i t}
$$

where $i$ indexes plants, $t$ indexes census years, $Y_{i t}$ is either average wage, labor productivity, or wage-bill-to-revenue ratio $^{11}, X_{i t}^{\tau}$ is an indicator of whether a plant is $\tau \in\{0,5,10,15,20\}$ years to its exit point (the last census it is observed), $E_{i t}^{\tau}$ is an indicator of whether a plant is $\tau$ $\in\{0,5,10,15,20\}$ years away from its entry point (the first census it is observed), $\mathbf{Z}_{i t}$ is a vector of additional plant-level controls, $T_{t}$ is a census year fixed effect, and $I_{i}$ is a 4-digit SIC industry fixed effect. ${ }^{12}$ The interaction term $T_{t} I_{i}$ is added to control for any industry and time specific

\footnotetext{
${ }^{9}$ For further information on the LRD, visit http://www.census.gov/ces/dataproducts/economicdata.html.

${ }^{10}$ Changes in benefits is another source of adjustments to compensation. The data contain information on benefits, which can be used to extend the definition of labor compensation beyond salary and wages.

${ }^{11}$ The total employment of a plant was restricted to the range 5 to 10,000 employees. In addition, the top and bottom percentiles of the three dependent variables were trimmed to reduce the influence of any outliers on the estimated coefficients.

${ }^{12}$ Note that the set of plants indicated by a given $E_{i t}^{\tau}$ includes plants that may also be in the set of plants indicated by some $X_{i t}^{\tau \prime}$ s.
} 
effects, including the effects of industry life-cycles. The omitted category, referred to as mature plants, is the plants that are more than twenty years away from their entry or exit, and the plants whose entry or exit dates do not fall into the sample period.

The dummy variables $X_{i t}^{\tau}$ and $E_{i t}^{\tau}$ capture life-cycle effects. They track the evolution of $Y_{i t}$ as a plant moves away from entry into maturity, and also as it approaches exit. Of interest are the parameters $\beta_{X}^{\tau}$ and $\beta_{E}^{\tau}$ that quantify the magnitudes of these life-cycle effects. $\beta_{X}^{\tau}$ is the effect on $Y_{i t}$ of being $\tau$ years away from exit, controlling for time from entry as identified by the dummies $E_{i t}^{\tau}$, in addition to other controls. Similarly, $\beta_{E}^{\tau}$ measures the effect on $Y_{i t}$ of being $\tau$ years from entry, controlling for time to exit identified by $X_{i t}^{\tau}$, in addition to other controls.

Specification I in Table 1 is what produces Figure 1, without the plant-level controls $\mathbf{Z}_{i t}$. Average wage is low for entering plants and gradually approaches that of mature plants. As plants get closer to exit, wages start to fall, but not as fast as they increase for surviving and aging entrants. Labor productivity is also much lower for entering plants, but improves as they age. Plants nearing exit have a much more substantial productivity disadvantage, visible even twenty years prior to exit. However, the pace of labor productivity growth in young plants exceeds the pace it declines in failing plants. This asymmetry manifests itself in the evolution of wage-billto-revenue ratio. For young plants, wages constitute a smaller fraction of revenue compared to mature plants, and for plants approaching exit wage bill claims an increasingly larger fraction of revenue.

The findings largely continue to hold when plant-level controls, $\mathbf{Z}_{i t}$, are added. In specification II, plant size, which has been found to be highly positively associated with wages (see, e.g., Brown and Medoff (1989)), is included, in addition to an indicator of whether the plant is part of a multiunit firm. Plant size is measured by total employment and specified as a cubic polynomial. While the magnitudes of life-cycle effects for average wage are now somewhat smaller in absolute value, their signs and significance resemble those in specification I. The most important difference is in the case of labor productivity for young plants. Compared to specification I, young plants now exhibit a much faster productivity growth, and seem to wipe out their productivity disadvantage vis á vis mature plants by their fifth year after entry. As a result, wage-bill-to-revenue ratio for entering plants is even lower, and stays lower longer as they age.

The findings are similar if we use unconditional estimates of the life-cycle effects, as shown in Figures 1d,e,f in the appendix. In these figures, the regressions (1) have on the right hand side either only the number of years to exit $\left(X_{i t}^{\tau}\right)$, or only the number of years from entry $\left(E_{i t}^{\tau}\right)$, in addition to time-industry interactions. In other words, the point estimates now capture the 
effect of being a certain number of years from entry (to exit) without conditioning on the number of years to exit (from entry). The unconditional estimates are not substantially different from the estimates in Figure 1, and allow making statements about the evolution of the key variables without explicit conditioning.

The results in Table 1 point to a fundamental asymmetry in how plant-level labor productivity reflects itself on wages. Wages rise faster than labor productivity does for young plants as they survive and age, and they fall slower than labor productivity does for failing plants. Consequently, wages represent a smaller share of revenue for young and surviving plants, but a higher share of revenue for those plants nearing exit. Surviving plants appear to have a payroll advantage: they pay their workers a smaller share of their revenues compared to mature plants. Plants approaching exit, however, are burdened with a wage bill that claims a larger fraction of their revenue compared to mature plants.

Does the evolution of key variables in Figure 1 vary across different worker types? A broad categorization of a plant's labor force into production versus non-production workers is available in the data. Table 2 shows the evolution of average wage and other key variables by these two worker types. This breakdown is only a crude distinction of function and skill among workers. Non-production workers category lumps together white-collar workers, including managers, sales, legal, and professional personnel, as well as many other types of employees who are not directly involved in production. ${ }^{13}$ The average wage of non-production workers is roughly double that of production workers, a difference that is also highly statistically significant. ${ }^{14}$ As suggested by this large gap, non-production workers may embody more skill, education, or human capital than production workers, at least on the average.

The first two columns of Table 2 present the evolution of the ratio of the number of nonproduction workers to the total number of workers, which is a proxy for a plant's skill composition. Regressions of the form in (1) were rerun with this ratio as the dependent variable $Y_{t}$. New plants have a low ratio relative to mature plants, but as plants age, the ratio increases. However, even twenty years after entry plants exhibit lower ratio relative to mature plants. As plants near exit, this ratio tends to go down, but not as fast as it rises in the case of young plants. Overall, there is a tendency for young plants to accumulate more skill as they age, and reduce skill as they approach exit.

\footnotetext{
${ }^{13}$ See Gujarati and Dars (1972) for a detailed description of these two types of workers, as defined by the US Census Bureau.

${ }^{14}$ In $1997 \mathrm{CM}$, the average wage for production workers was about $\$ 21,000$, compared to about $\$ 39,000$ for non-production workers.
} 
Average wages for both types of workers start out low for new plants relative to mature ones, but increase as plants age. Twenty years after entry, plants have about the same average wage for non-production workers as mature plants, whereas they exhibit about $\$ 200$ lower average wage compared to mature plants for production workers. As a plant approaches exit, the average wages of both types of workers fall, with a larger decline for non-production workers. Plants in their last census year on average pay about $\$ 1,500$ less to their production workers and about $\$ 4,500$ less to their non-production workers, compared to the mature plants. One concern is that these magnitudes are absolute - not measured relative to the average wage in each category of workers. The regressions using logarithm of average wage address this issue. Even when the change in average wage for a worker type is measured as a percentage of the average wage for that type, the pattern essentially remains the same: the average wage of non-production workers rises faster than that of production workers as a new plant ages, and it also declines faster as a plant approaches exit. The relatively higher inertia in production workers' wages may stem from several reasons. One reason is that they are more likely to be unionized. Another may be that they perform essential tasks for production and are harder to dispense with if a plant is to continue production during episodes of persistent low profitability.

The last four columns of Table 2 present the evolution of wage-bill-to-revenue ratio for production and non-production workers. For both types of workers, this ratio starts out low in new plants compared to mature plants and gradually increases. However, failing plants seem to have a higher payroll share of revenue compared to mature plants when production workers are considered. This pattern does not apply to non-production workers. The evolutions of average wage and wage-bill-to-revenue ratio in Table 1 appear to be driven by two factors: (i) the asymmetry in the evolution of worker composition - a shift towards non-production workers as young plants age, and a shift towards production workers as plants approach exit, and (ii) the slower rise and decline in the average wage of production workers compared to that of non-production workers.

\section{The model}

The model is motivated by the empirical findings in the previous section. It considers both the quantity and quality of labor as factors of production. A key ingredient is the ability of plants to alter their wages through adjustment of worker quality. The higher the quality of labor a plant uses, the larger the output. But higher quality labor comes at higher wages. Labor quality captures the average skill level of the plant's labor force, which can be altered by the plant through 
hiring, firing, and other means, such as investment into a worker's skill acquisition or training. Labor quality can also be interpreted as a worker's effort level or the quality of his output, both of which may be positively associated with wage.

Consider an industry with a large number of plants, each of which is too small to influence industry aggregates. Plants can be price-takers, or they may be local monopolies and can set their prices given their downward sloping demand functions. There is an infinite number of discrete time periods. Plants receive random shocks to their profitability each period. Plants are also exposed to economy and industry-wide shocks to an exogenous wage rate per unit of labor quality. There is a large number of workers with varying quality levels available for hire by plants at that exogenous wage rate.

\subsection{Adjustment cost for wages}

A plant chooses the quantity and average quality of its labor force, as well as other inputs, to generate output through a Cobb-Douglas production technology. The profit function of a plant at any period $t$ is

$$
\begin{aligned}
\Pi\left(q_{t}, L_{t} ; q_{t-1}, L_{t-1}, w_{t}, w_{t-1}, \theta_{t}\right)= & \theta_{t} L_{t}^{\alpha} q_{t}^{\gamma}-w_{t} q_{t} L_{t} \\
& -\left[I_{t}^{U} \frac{\lambda^{U}}{2}+I_{t}^{D} \frac{\lambda^{D}}{2}\right]\left(\frac{w_{t} q_{t}-w_{t-1} q_{t-1}}{w_{t-1} q_{t-1}}\right)^{2} w_{t-1} q_{t-1} L_{t-1}-F .
\end{aligned}
$$

In the production function represented by the first term on the left hand side of $(2), L_{t}$ is the quantity of labor, $q_{t}$ is the average quality or skill level per unit of labor, and $\theta_{t} \geq 0$ is a profitability shock that includes aggregate and idiosyncratic shocks, as well as the output price. The parameters of the production function satisfy the restrictions $\alpha, \gamma \in(0,1)$ and $\alpha+\gamma<1$. These parameters are determined by the underlying shares of $L_{t}, q_{t}$, and other inputs in production. ${ }^{15}$

In the cost function represented by the remaining terms on the left hand side of $(2), w_{t}$ is the wage per unit of labor quality that evolves exogenously, and $\lambda^{U} \geq 0$ and $\lambda^{D} \geq 0$ are the parameters of the quadratic adjustment costs associated with upward and downward adjustments

\footnotetext{
${ }^{15}$ Suppose the plant is a price-taker and the underlying production function is given by $\widetilde{\theta}_{t}\left(M_{t}^{1-\widetilde{\alpha}-\widetilde{\gamma}} L_{t}^{\widetilde{\alpha}} q_{t}^{\widetilde{\gamma}}\right)^{\delta}$, where $M_{t}$ is some other input that can be costlessly adjusted, $\widetilde{\alpha}, \widetilde{\gamma} \in(0,1)$ are the shares of labor quantity and quality in output such that $\widetilde{\alpha}+\widetilde{\gamma}<1$, and $\delta \in(0,1)$ reflects decreasing returns at the plant level to some fixed input (such as capital or physical space). If the unit price of $M_{t}$ is $m_{t}$, the optimization only with respect to $M_{t}$ leads to the production function in (2) where $\alpha=\frac{\delta \widetilde{\alpha}}{1-\delta(1-\widetilde{\alpha}-\widetilde{\gamma})}, \gamma=\frac{\delta \widetilde{\gamma}}{1-\delta(1-\widetilde{\alpha}-\widetilde{\gamma})}$, and $\theta_{t}$ is a function of $\tilde{\theta}_{t}, \widetilde{\alpha}, \widetilde{\gamma}, \delta, m_{t}$ and output price $p_{t}$. A similar interpretation applies if a plant has local market power, in which case $\delta$ can be interpreted as the elasticity of demand.
} 
in average wage, $w_{t} q_{t}$, indicated by $I_{t}^{U} \equiv I\left(w_{t} q_{t}>w_{t-1} q_{t-1}\right)$ and $I_{t}^{D} \equiv I\left(w_{t} q_{t} \leq w_{t-1} q_{t-1}\right)$. The quadratic is in terms of the conventional growth rate of $w_{t} q_{t}$ over its previous period value $w_{t-1} q_{t-1} \cdot{ }^{16}$ The adjustment in average wage applies to total wage bill from the previous period $w_{t-1} q_{t-1} L_{t-1}$, implying that the adjustment cost is proportional to firm size measured by $L_{t-1}$. The adjustment in average wage has two sources: exogenous changes in $w_{t}$, and the plant's choice of $q_{t}$, which also depends on $w_{t}$ and $\theta_{t}$. When the unit cost of worker quality changes, the plant has to incur an adjustment cost in wages even when it does not adjust the average quality of its labor force. These two dimensions of adjustment are not separately identified. Finally, $F$ is a fixed cost of operation that is avoidable only if the plant exits.

Labor quality $q_{t}$ can alternatively be viewed as the idiosyncratic component of a plant's average wage, which can be positively associated with the quality of the job a worker produces or the effort that the worker exerts. If the idiosyncratic component is lower, the worker exerts less effort or the quality of his output declines, resulting in lower output for the plant. The average wage $w_{t} q_{t}$ is then a multiplicative representation of its exogenous common $\left(w_{t}\right)$ and endogenous idiosyncratic $\left(q_{t}\right)$ components. $^{17}$

The distribution of $\theta_{t}$ is given by the c.d.f. $H\left(\theta_{t} \mid \theta_{t-1}\right)$, which specifies the general dependence of a period's profitability shock on its previous value. Similarly, the distribution of $w_{t}$ is given by the c.d.f. $G\left(w_{t} \mid w_{t-1}\right)$. The random variables $w_{t+j}$ and $\theta_{t+k}$ are assumed to be independent for $j \neq k$. The distributions $H$ and $G$ are assumed to be monotone in $\theta_{t-1}$ and $w_{t-1}$, respectively. ${ }^{18}$ Such monotonicity is satisfied by i.i.d. distributions, as well as by more persistent processes. The exact forms of $H$ and $G$ are not specified. ${ }^{19}$ In the estimation, the profitability and wage processes will be driven by the data, instead of being specified as part of the model.

It can be verified that the profit function $\Pi$ is strictly increasing in $\theta_{t}$, and strictly decreasing

\footnotetext{
${ }^{16} \mathrm{An}$ alternative growth rate is also used for robustness, as explained below.

${ }^{17}$ An additive form, $w_{t}+v_{t}$, can also be specified, where $v_{t}$ is the plant-specific component of wage. Now, write $w_{t}+v_{t}=w_{t}\left(1+\frac{v_{t}}{w_{t}}\right)$ and define a worker's effort or the quality of his output proportional to wage as $e_{t}=k v_{t}$. Letting $q_{t}=\left(1+\frac{e_{t}}{k w_{t}}\right)$, one can obtain the multiplicative specification $w_{t} q_{t}=w_{t}+v_{t}$. Because $w_{t}$ is common across firms, $q_{t}$ preserves the ranking of the idiosyncratic component across plants. Choice of $q_{t}$ by a plant is equivalent to choice of $e_{t}$ in this case.

${ }^{18}$ Specifically, for any non-decreasing function $u, \int u\left(\theta_{t}\right) d H\left(\theta_{t} \mid \theta_{t-1}\right)$ is non-decreasing in $\theta_{t-1}$. Similarly, For any non-increasing function $v, \int v\left(w_{t}\right) d H\left(w_{t} \mid w_{t-1}\right)$ is non-increasing in $w_{t-1}$. These assumptions are needed for the existence and monotonicity of a plant's value function.

${ }^{19}$ Prior evidence suggests that $\theta_{t}$ is persistent. A frequent specification (see, e.g., Hopenhayn (1992), Fishman and Rob (2002)) is for any two shocks $\theta_{t-1}>\theta_{t-1}^{\prime}, H\left(\theta_{t} \mid \theta_{t-1}\right)$ first order stochastically dominates $H\left(\theta_{t} \mid \theta_{t-1}^{\prime}\right)$. Some studies (e.g., Abraham and White (2006)) find high persistence in productivity at the firm level.
} 
in $L_{t-1}$ and $w_{t} .{ }^{20}$ Define the state variable for a plant as $\mathbf{s}_{t}=\left(q_{t-1}, L_{t-1}, w_{t}, w_{t-1}, \theta_{t}\right)$. The plant's decision to continue operation after observing $\theta_{t}$ is denoted by the discrete choice $X_{t}$ such that $X_{t}=0$ if the plant exits, and $X_{t}=1$ if the plant continues. The value of a plant can then be written as

$$
V_{t}\left(\mathbf{s}_{t}\right) \equiv \max _{X_{t}, L_{t}, q_{t}} X_{t}\left(\Pi\left(q_{t}, L_{t} ; \mathbf{s}_{t}\right)+\beta E\left[V_{t+1}\left(\mathbf{s}_{t+1}\right)\right]\right)
$$

where the plant's exit value is normalized to zero and $\beta$ is the discount factor. The expectation in (3) is taken over all possible values of $\theta_{t+1}$ conditional on $\theta_{t}$, and over all possible values of $w_{t+1}$ conditional on $w_{t}$.

Given the assumptions of the model, dynamic programming arguments in Stokey and Lucas (1989) guarantee the existence of a unique time-invariant value function $V$, which is strictly increasing in $\theta_{t}$ and strictly decreasing in $L_{t-1}$ and $w_{t}{ }^{21}$ Because $V$ is monotonic in $\theta_{t}$, exit occurs the first time $\theta_{t}$ satisfies $V\left(\mathbf{s}_{t}\right) \leq 0$.

At the beginning of every period, there is a large number (a continuum) of ex-ante identical potential entrants which can enter the industry as long as it is profitable to do so. The expected value from entry is $V_{t}^{e}=E\left[V\left(\mathbf{s}_{t}\right)\right]$, where an entrant's initial state $\mathbf{s}_{t}=\left\{0,0, w_{t}, w_{t-1}, \theta_{t}\right\}$ reflects the fact that its prior labor quality and quantity are both zero, and the initial profitability draw after entry comes from a continuous distribution. There is a sunk entry cost of $\kappa>0$. Positive entry in period $t$ implies $V_{t}^{e}=\kappa$, and no entry occurs when $V_{t}^{e}<\kappa$.

Let $V_{i}$ denote the derivative of $V$ with respect to its $i^{\prime}$ th argument. ${ }^{22}$ A plant's choice of $L_{t}$ conditional on continuing $\left(X_{t}=1\right)$ satisfies

$$
\alpha \theta_{t} L_{t}^{\alpha-1} q_{t}^{\gamma}-w_{t} q_{t}+\beta E\left[V_{2}\left(\mathbf{s}_{t+1}\right)\right]=0
$$

where

$$
E\left[V_{2}\left(\mathbf{s}_{t+1}\right)\right]=-E\left[\left(I_{t+1}^{U} \frac{\lambda^{U}}{2}+I_{t+1}^{D} \frac{\lambda^{D}}{2}\right)\left(\frac{w_{t+1} q_{t+1}-w_{t} q_{t}}{w_{t} q_{t}}\right)^{2}\right] w_{t} q_{t}
$$

The first term on the left hand side of (4) is the marginal benefit from a small change in the quantity of labor, and the second and third terms give the associated marginal cost: the change in

\footnotetext{
${ }^{20}$ Monotonicity in $\theta_{t}, w_{t}$, and $L_{t-1}$ follow from straightforward differentiation, except at $w_{t}=\frac{q_{t-1}}{q_{t}} w_{t-1}$, where $\Pi$ is non-differentiable with respect to $w_{t}$ when $\lambda^{U} \neq \lambda^{D}$.

${ }^{21}$ Assumptions 9.4, 9.5, 9.6, and 9.7 in Stokey and Lucas (1989) are satisfied for the firm's dynamic programming. Furthermore, Assumptions 9.8 and 9.9 are satisfied for the state variables $L_{t-1}$ and $w_{t}$. Monotonicity then follows from Theorem 9.7. Similarly, assumptions 9.13-9.15 are satisfied for the state variable $\theta_{t}$. Monotonicity then follows from Theorem 9.11.

${ }^{22}$ Note that the derivative of $V$ with respect to $q_{t}$ does not exist at $q_{t}=\frac{w_{t-1}}{w_{t}} q_{t-1}$ when $\lambda^{U} \neq \lambda^{D}$.
} 
current wage bill and the change in the next period's expected adjustment cost. A plant's choice of $q_{t}$ conditional on continuing $\left(X_{t}=1\right)$ satisfies

$$
\gamma \theta_{t} L_{t}^{\alpha} q_{t}^{\gamma-1}-w_{t} L_{t}-\left[I_{t}^{U} \lambda^{U}+I_{t}^{D} \lambda^{D}\right]\left(\frac{w_{t} q_{t}-w_{t-1} q_{t-1}}{w_{t-1} q_{t-1}}\right) w_{t} L_{t-1}+\beta E\left[V_{1}\left(\mathbf{s}_{t+1}\right)\right]=0,
$$

where

$$
E\left[V_{1}\left(\mathbf{s}_{t+1}\right)\right]=E\left[\left(I_{t+1}^{U} \frac{\lambda^{U}}{2}+I_{t+1}^{D} \frac{\lambda^{D}}{2}\right) \frac{L_{t}}{w_{t}^{2} q_{t}^{2}}\left(w_{t+1}^{2} q_{t+1}^{2}-w_{t}^{2} q_{t}^{2}\right) w_{t}\right] .
$$

Once again, the first term on the left hand side of (6) is the marginal benefit from a small change in quality of labor and the remaining terms are the associated marginal cost: the change in current wage bill, the change in current adjustment cost, and the change in the next period's expected adjustment cost. The two first order conditions (4) and (6) simultaneously and implicitly determine the policies $L\left(\mathbf{s}_{t}\right)$ and $q\left(\mathbf{s}_{t}\right)$. Let $\Pi^{*}\left(\mathbf{s}_{t}\right)$ be the period profit function evaluated at $L\left(\mathbf{s}_{t}\right)$ and $q\left(\mathbf{s}_{t}\right)$. The continuation policy $X\left(\mathbf{s}_{t}\right)$ is then given by the following

$$
X\left(\mathbf{s}_{t}\right)=\left\{\begin{array}{cc}
0 & \text { if } \Pi^{*}\left(\mathbf{s}_{t}\right)+\beta E\left[V\left(\mathbf{s}_{t+1}\right)\right] \leq 0 \\
1 & \text { otherwise }
\end{array}\right.
$$

One can assess the implications of the model on wage bill-to-revenue ratio. Using (4), the wage bill can be expressed as a percentage of revenue as

$$
f_{t}=\frac{L_{t} w_{t} q_{t}}{\theta_{t} L_{t}^{\alpha} q_{t}^{\gamma}}=\alpha+\beta \frac{E\left[V_{2}\left(\mathbf{s}_{t+1}\right)\right] L_{t}}{\theta_{t} L_{t}^{\alpha} q_{t}^{\gamma}} .
$$

Using (5) in (8) one then obtains

$$
f_{t}=\frac{\alpha}{1+\beta \eta_{t+1}}
$$

where

$$
\eta_{t+1}=E_{w_{t}}\left[E_{\theta_{t+1}}\left[\left(I_{t+1}^{U} \frac{\lambda^{U}}{2}+I_{t+1}^{D} \frac{\lambda^{D}}{2}\right)\left(\frac{w_{t+1} q_{t+1}-w_{t} q_{t}}{w_{t} q_{t}}\right)^{2} \mid \theta_{t}\right] \mid w_{t}\right],
$$

is the expected value of the squared percent adjustment in the next period conditional on $\theta_{t}$ and $w_{t}$. An implication of (9) is that higher absolute expected percent adjustment in average wage in the next period is accompanied by a lower share of labor in current period revenue. This result follows because the plant's current wage bill and its expected cost of adjustment in wages next period must be compensated by the labor's share of current revenue.

The expectation in (10) is taken over both $w_{t+1}$ and $\theta_{t+1}$, conditional on $\theta_{t}$ and $w_{t}$. If $\eta_{t+1}$ is strictly increasing in $\theta_{t}$ conditional on $w_{t}$, better profitability shocks (higher $\theta_{t}$ ) imply a lower $f_{t}$. The outer expectation in (10) applies to the stochastic process $w_{t}$, which is common to all firms and independent of $\theta_{t}$. Thus, in comparing the value of (9) across plants, one can focus on 
the inner expectation over $\theta_{t+1}$ conditional on $\theta_{t}$. Consider the case where the policies $L\left(\mathbf{s}_{t}\right)$ and $q\left(\mathbf{s}_{t}\right)$ are both strictly increasing in $\theta_{t}$. The appendix shows that such monotonicity holds under certain conditions. If $\theta_{t}$ follows an i.i.d. process, the expected average wage for the next period is the same for all firms, implying that $\eta_{t+1}$ is higher, and $f_{t}$ is lower, for values of $\theta_{t}$ away from the mean $E\left[\theta_{t} \mid \theta_{t-1}\right]$. However, if $\theta_{t}$ is persistent over time, e.g. if higher values of $\theta_{t}$ makes even higher values of $\theta_{t+1}$ more likely, then a high value of $\theta_{t}$ can lead to a higher expected $\theta_{t+1}$, and, hence, a lower $f_{t}$, especially when $\lambda^{U}<\lambda^{D}$.

\subsection{Adjustment cost for wages and employment}

Consider now adjustment cost for employment, in addition to that for wages. The period profit function of a plant is now

$$
\begin{aligned}
\Pi\left(q_{t}, L_{t} ; w_{t}, q_{t-1}, w_{t-1}, L_{t-1}, \theta_{t}\right)= & \theta_{t} L_{t}^{\alpha} q_{t}^{\gamma}-w_{t} q_{t} L_{t} \\
& -\left[I_{t}^{U} \frac{\lambda^{U}}{2}+I_{t}^{D} \frac{\lambda^{D}}{2}\right]\left(\frac{w_{t} q_{t}-w_{t-1} q_{t-1}}{w_{t-1} q_{t-1}}\right)^{2} w_{t-1} q_{t-1} L_{t-1} \\
& -\left[J_{t}^{U} \frac{\nu^{U}}{2}+J_{t}^{D} \frac{\nu^{D}}{2}\right]\left(\frac{L_{t}-L_{t-1}}{L_{t-1}}\right)^{2} L_{t-1}-F,
\end{aligned}
$$

where $\nu^{U} \geq 0$ and $\nu^{D} \geq 0$ are the parameters of the quadratic adjustment cost associated with upward and downward adjustment of employment, indicated by $J_{t}^{U} \equiv I\left(L_{t}>L_{t-1}\right)$ and $J_{t}^{D} \equiv I\left(L_{t} \leq L_{t-1}\right)$. The employment adjustment cost function follows the standard quadratic formulation (e.g. Cooper and Haltiwanger (2005) and Cooper and Willis (2009)). Both the wage and employment adjustment costs are proportional to firm size measured by $L_{t-1}$. The specification of adjustment costs takes into account two margins of adjustment: an intensive margin of adjustment that applies only to average wage, and an extensive margin that applies only to employment. However, these two margins are not independent. Adjustment in average wage affects a plant's current and future employment decision, and adjustment in employment in turn influences current and future choices of average wage.

For a continuing plant, the first order condition for $q_{t}$ is the same as (6). For $L_{t}$, the first order condition now becomes ${ }^{23}$

$$
\alpha \theta_{t} L_{t}^{\alpha-1} q_{t}^{\gamma}-w_{t} q_{t}-\left[J_{t}^{U} \nu^{U}+J_{t}^{D} \nu^{D}\right]\left(\frac{L_{t}-L_{t-1}}{L_{t-1}}\right)+\beta E\left[V_{2}\left(\mathbf{s}_{t+1}\right)\right]=0 .
$$

\footnotetext{
${ }^{23}$ Note that $V$ is now non-differentiable with respect to $L_{t}$ at $L_{t}=L_{t-1}$ when $\nu^{U} \neq \nu^{D}$.
} 


\subsection{Adjustment cost with alternative growth rates}

As an alternative to the adjustment cost specification used so far, an adjustment cost which allows for symmetric and bounded growth rates can also be considered. The alternative adjustment cost specifications for average wage and employment are given by replacing the denominators of the squared terms in (2) and (11) with $\frac{1}{2}\left(w_{t} q_{t}+w_{t-1} q_{t-1}\right)$ and $\frac{1}{2}\left(L_{t}+L_{t-1}\right)$, respectively. These alternative specifications restrict the growth rates in average wage or employment to the interval $[-2,2]$. These growth rates have some desirable features compared to the conventional growth rate, such as robustness to outliers and boundedness for the case of new entrants whose initial average wage and employment are both zero. ${ }^{24}$ The appendix contains the first order conditions for the adjustment costs with alternative growth rates.

\section{Estimation}

\subsection{Estimation with adjustment cost for wages}

Consider first the model with adjustment cost in wages only. Condition (6) can be rewritten after multiplying through by $q_{t}$ as

$$
\gamma \theta_{t} L_{t}^{\alpha} q^{\gamma}-w_{t} q_{t} L_{t}-\left[I_{t}^{U} \lambda^{U}+I_{t}^{D} \lambda^{D}\right]\left(\frac{w_{t} q_{t}-w_{t-1} q_{t-1}}{w_{t-1} q_{t-1}}\right) w_{t} q_{t} L_{t-1}+\beta E\left[V_{1}\left(\mathbf{s}_{t+1}\right)\right] q_{t}=0 .
$$

Multiplication by $q_{t}$ ensures that average wage $w_{t} q_{t}$ appears in the first order condition, rather than just $w_{t}$. The former can be calculated using a plant's wage bill and employment, whereas the latter is not directly observed.

Profit maximizing conditions are not likely to be exactly fulfilled for several reasons such as managerial errors originating from inertia and ignorance. Such errors can result in deviations from the plant's ideal choices. Another source of deviations from optimality ex-post is the difference between anticipated and realized prices. These idiosyncratic errors and deviations can be assumed to be randomly distributed over plants. Following Hansen and Singleton (1982), the ex-post error can be expressed, using (7) and (13), as a function of the parameters $\Phi=\left\{\alpha, \gamma, \lambda^{U}, \lambda^{D}\right\}$

$$
\begin{aligned}
\varepsilon_{t, t+1}(\Phi)= & -\gamma \theta_{t} L_{t}^{\alpha} q_{t}^{\gamma}+w_{t} q_{t} L_{t}+\left[I_{t}^{U} \lambda^{U}+I_{t}^{D} \lambda^{D}\right]\left(\frac{w_{t} q_{t}-w_{t-1} q_{t-1}}{w_{t-1} q_{t-1}}\right) w_{t} q_{t} L_{t-1} \\
& -\beta\left[I_{t+1}^{U} \frac{\lambda^{U}}{2}+I_{t+1}^{D} \frac{\lambda^{D}}{2}\right] \frac{L_{t}}{w_{t} q_{t}}\left(w_{t+1}^{2} q_{t+1}^{2}-w_{t}^{2} q_{t}^{2}\right)
\end{aligned}
$$

\footnotetext{
${ }^{24}$ See Davis, Haltiwanger, and Schuh (1996) for a discussion of this growth measure.
} 
The ex-post error in labor choice, after using (4) and (5), is

$$
\eta_{t, t+1}(\Phi)=-\alpha \theta_{t} L_{t}^{\alpha-1} q_{t}^{\gamma}+w_{t} q_{t}+\beta\left[I_{t+1}^{U} \frac{\lambda^{U}}{2}+I_{t+1}^{D} \frac{\lambda^{D}}{2}\right]\left(\frac{w_{t+1} q_{t+1}-w_{t} q_{t}}{w_{t} q_{t}}\right)^{2} w_{t} q_{t} .
$$

Equations (14) and (15) are estimated using a GMM framework. The parameters to be estimated are $\Phi=\left\{\alpha, \gamma, \lambda^{U}, \lambda^{D}\right\}$. The discount factor is set to $\beta=0.78$ for the quinquennial data, which corresponds to a $95 \%$ discount rate for annual data.

The estimation can be readily applied to continuing plants. For exiting plants, the decision variables are not observed for the period after they exit. However, the event of exit contains additional information about the parameters of interest, as exit probability depends on the parameters

$$
\operatorname{Pr}(\text { Exit at time } t)=\operatorname{Pr}\left(V\left(\mathbf{s}_{t}\right) \leq 0\right)=\operatorname{Pr}\left(\theta_{t}<\theta^{*}\left(q_{t-1}, L_{t-1}, w_{t}, w_{t-1}\right)\right) \text {, }
$$

where $\theta^{*}\left(q_{t-1}, L_{t-1}, w_{t}, w_{t-1}\right)$ is the threshold profitability shock such that a plant with $\mathbf{s}_{t}=$ $\left(\theta_{t}, q_{t-1}, L_{t-1}, w_{t}, w_{t-1}\right)$ and $\theta_{t}<\theta^{*}$ exits. Pakes (1994) shows that one can substitute the discrete continuation policy $X\left(\mathbf{s}_{t}\right)$ into the expected discounted future profits and proceed as in the case of continuing plants. Thus, for a plant that continues from time $t+1$ to $t+2, X\left(\mathbf{s}_{t+1}\right)=1$ and the ex-post errors are as defined earlier. For a plant that exits at time $t+1, X\left(\mathbf{s}_{t+1}\right)=0$ and the ex-post errors become

$$
\begin{gathered}
\varepsilon_{t, t+1}(\Phi)=-\gamma \theta_{t} L_{t}^{\alpha} q_{t}^{\gamma}+w_{t} q_{t} L_{t}+\left[I_{t}^{U} \lambda^{U}+I_{t}^{D} \lambda^{D}\right]\left(\frac{w_{t} q_{t}-w_{t-1} q_{t-1}}{w_{t-1} q_{t-1}}\right) w_{t} q_{t} L_{t-1}, \\
\eta_{t, t+1}(\Phi)=-\alpha \theta_{t} L_{t}^{\alpha-1} q^{\gamma}+w_{t} q_{t} .
\end{gathered}
$$

The GMM estimation can be carried out using equations (14) and (15) for continuing plants and equations (16) and (17) for exiting plants. It is important to include exiting plants in the estimation as not doing so could induce bias in both the estimated production function and adjustment cost parameters. The estimation is done separately for continuing plants and all plants (continuing and exiting) to assess this potential bias.

\subsection{Estimation with adjustment cost for wages and employment}

For the case with both employment and wage adjustment cost, the ex-post error for $L_{t}$ is

$$
\begin{aligned}
\eta_{t, t+1}(\Phi)= & -\alpha \theta_{t} L_{t}^{\alpha-1} q_{t}^{\gamma}+w_{t} q_{t}+\left[J_{t}^{U} \nu^{U}+J_{t}^{D} \nu^{D}\right]\left(\frac{L_{t}-L_{t-1}}{L_{t-1}}\right) \\
& +\beta\left[I_{t+1}^{U} \frac{\lambda^{U}}{2}+I_{t+1}^{D} \frac{\lambda^{D}}{2}\right]\left(\frac{w_{t+1} q_{t+1}-w_{t} q_{t}}{w_{t} q_{t}}\right)^{2} w_{t} q_{t} \\
& -\beta\left[J_{t+1}^{U} \frac{\nu^{U}}{2}+J_{t+1}^{D} \frac{\nu^{D}}{2}\right]\left(\frac{L_{t+1}^{2}-L_{t}^{2}}{L_{t}^{2}}\right) .
\end{aligned}
$$


The ex-post error for $q_{t}$ is the same as (14).

For exiting plants, the ex-post error for $L_{t}$ is

$$
\eta_{t, t+1}(\Phi)=-\alpha \theta_{t} L_{t}^{\alpha-1} q^{\gamma}+w_{t} q_{t}+\left[J_{t}^{U} \nu^{U}+J_{t}^{D} \nu^{D}\right]\left(\frac{L_{t}-L_{t-1}}{L_{t-1}}\right)
$$

and the ex-post error for $q_{t}$ is the same as (16). The parameters to be estimated are now $\Phi=$ $\left\{\alpha, \gamma, \lambda^{U}, \lambda^{D}, \nu^{U}, \nu^{D}\right\}$.

The estimation involves endogenous variables that are simultaneously determined. These are current revenue, employment, and average wage. The instruments used for endogenous variables are lagged revenue, value added, wage bill, average wage, and their interactions with current-period revenue, employment, average wage and value added, all deflated. ${ }^{25}$ Similar estimation procedures apply to the case of adjustment cost with alternative growth rate using the first order conditions in the appendix.

\section{Results}

The GMM estimates of parameters using the entire sample of manufacturing plants are reported in Table 3. Two measures of revenue are used alternatively: deflated total value of shipments (top panel) and deflated value added (bottom panel). Adjustment costs with both the conventional and the alternative growth rates are considered. The estimates in specifications I and III pertain to continuing plants. For each census year $t$, continuing plants are the ones that are observed in census years $t$ and $t+1$. The estimates in specifications II and IV include all plants. For each census year $t$, all plants include continuing plants and the exiting plants, which are observed in census years $t-1$ and $t$, but not at time $t+1$. Both the model with wage adjustment only (specifications I and II), and the model with wage and employment adjustment (specifications III and IV) are estimated. ${ }^{26}$

In all specifications, the estimates for the production function parameters $\alpha$ and $\gamma$ are very precise, have the expected signs, and fall in the interval $(0,1)$. As shown in the top panel, the estimated value of $\alpha+\gamma$ when revenue is measured by the value of shipments range from 0.17 to 0.55 . This range also contains the estimated labor share of output, about 0.40 , that is obtained by

\footnotetext{
${ }^{25}$ The results were not significantly different when twice-lagged versions of the variables were also used as instruments.

${ }^{26}$ In all specifications in Table 3, the top and bottom $1 \%$ of the plant level distributions of average wage, wage bill-to-revenue ratio, and labor productivity were trimmed to reduce the influence of some major outliers. The total employment of a plant was also restricted to the range 5 to 10, 000 employees.
} 
estimating the specified Cobb-Douglas production on the same sample of plants in a static model without the adjustment costs. When value added is used as the revenue measure in the bottom panel, the estimates of $\alpha$ and $\gamma$ are much higher, and still highly significant. The estimates of $\alpha+\gamma$ are in the range $0.49-0.83$, which contains the point estimate of labor share, about 0.80 , obtained from the static version of the model without adjustment costs based on the same sample of plants. The estimates of $\gamma$ exceed those of $\alpha$ in almost all specifications in the top and bottom panels, pointing to the importance of the labor quality share in the specified production function.

In most specifications, the estimates of the adjustment cost parameters have the expected signs, and all are highly significant. In some cases, the estimated upward adjustment cost parameters, $\lambda^{U}$ and $\nu^{U}$, are negative, with relatively small absolute values compared to other adjustment cost parameter estimates. These cases can result from a combination of remaining outliers, measurement error, and sampling errors. Overall, the estimates reveal significant asymmetry in adjustment costs. Except for one case (specification II with alternative growth rate), downward adjustment costs parameters are much higher than upward adjustment cost parameters, both for wage and employment adjustment. Furthermore, downward adjustment cost parameters are generally larger in absolute value when all plants are considered (specifications II and IV), compared to the case of continuing plants only (specifications I and III). This difference suggests that exiting plants face steeper downward adjustment costs than continuing ones. The adjustment cost parameter estimates are generally smaller under alternative growth rates, because the alternative growth rates are bounded and robust to outliers in wage and employment growth.

Table 3 was obtained from estimating the model without any constraints. A constraint on the model's adjustment cost parameters, however, is that they must be non-negative. Table 3A in the appendix presents the GMM estimates under the non-negativity constraints for adjustment cost parameters. If the model's specification is not largely at odds with the data, moving from the unconstrained to the constrained estimation should not result in drastic sign and significance changes in adjustment cost parameters, such as a shift from being negative and significant to being positive and significant. Estimates of $\alpha$ and $\gamma$ in Table 3A are generally similar to those in Table 3 , and they are actually somewhat larger in cases where revenue is measured by value added. Also notable is the fact that almost all of the negative estimates of upward adjustment cost parameters in Table 3 are now zero - none has become positive and significant. This observation suggests that the upward adjustment cost parameters may indeed be not far from zero, and the negative estimates in Table 3 are not likely a result of a gross model misspecification, rather potentially attributable to other factors such as measurement error. The estimates of downward adjustment 
costs also remain significant and positive in Table $3 \mathrm{~A}$. The results in Table $3 \mathrm{~A}$ overall support the main conclusions from Table 3.

Because the percent adjustment in wages and employment applies to different bases in the adjustment cost specifications, it is not appropriate to simply compare the estimated magnitudes of $\lambda^{U}$ and $\nu^{U}$, or of $\lambda^{D}$ and $\nu^{D}$, to gauge the relative importance of different adjustment costs. One can assess the importance of the cost of adjustment for wages versus employment by comparing their estimated shares in a plant's current revenue. These static shares do not take into account the dynamic effects of adjustments. The adjustment cost incurred in the current period changes future revenues. Thus, it is possible for adjustment cost shares of revenue to exceed one. For instance, a plant may incur a net loss in the current period to ensure future profitability.

Table 4 presents quartiles for the estimated revenue shares of adjustment costs based on the parameter estimates in Table 3 for specifications I-IV using value added as the revenue measure with adjustment costs under conventional growth rates. Panel (a) considers estimates from the models using continuing plants only, corresponding to specifications I and III in Table 3. For the model with wage adjustment only, at the median adjustment cost, the adjustment cost is $1.2 \%$ of revenue when all directions of adjustment are considered together, and around $0.4 \%$ and $6.7 \%$ when upward and downward adjustments are considered, respectively. For the model with both wage and employment adjustment, wage adjustment cost is about $2.8 \%$ of revenue at the median wage adjustment cost, and upward wage adjustment cost constitutes about $1.1 \%$ of revenue, while downward wage adjustment cost makes up about 8.2\% of revenue. Employment adjustment cost has a significant share (nearly 20\%) of revenue at the median employment adjustment cost when downward employment adjustments are considered. For upward employment adjustments, this share is about $6 \%$ at the median employment adjustment cost.

A similar pattern emerges in panel (b) of Table 4, which focuses on the estimated parameters using all plants, corresponding to specifications II and IV in Table 3. For the model with wage adjustment only, upward and downward wage adjustment costs make up, respectively, about $0.3 \%$ and $4 \%$ of revenue at the median wage adjustment cost. For the model with both adjustment margins, these shares are about $0.4 \%$ and $5.4 \%$, respectively. For employment adjustment, upward adjustment cost is about $2 \%$ of revenue, but the downward adjustment cost constitutes about $22 \%$ of revenue, both measured at the median employment adjustment cost.

Adjustment costs tend to be a much larger fraction of revenue when only the exiting plants are considered, as panel (c) of Table 4 demonstrates. For all model specifications and for both upward and downward adjustment, the shares in panel (c) are much higher compared to panels 
(a) and (b). In particular, at the 3rd quartile of the adjustment cost distribution downward wage adjustment cost makes up around $30 \%$ of revenue for the model with wage adjustment only, and about $40 \%$ of revenue for the model with both adjustments. These magnitudes suggest that downward adjustment costs can be a substantial burden for plants, especially for those nearing exit.

How much do adjustment costs in wages change over the life-cycle of a plant? The evolution of adjustment costs along the plant life-cycle is shown in Figure 2. The estimates in Figure 2 are based on the specification with wage adjustment cost only and conventional growth rates. For

plants that are five years from their first census, wage adjustment cost makes up about $1.6 \%$ of revenue at the median. This share increases slightly as new plants age and declines to about $1 \%$ by the time a plant is 20 years away from entry. An almost reversal of this pattern emerges for plants approaching exit. The wage adjustment cost grows to about $1.6 \%$ of a plant's revenue five years before its exit, up from about $0.8 \%$ when a plant stands twenty years from exit.

Overall, the estimates of production function parameters suggest that the quality of labor is an important input in production when compared to the quantity of labor. In many cases, the quality's share of revenue exceeds that of quantity, as indicated by the relative magnitudes of the estimated $\alpha$ and $\gamma$. Both the quality and quantity margins of adjustment matter. Evidence also points to highly asymmetric adjustment costs both for wages and employment. Upward adjustment costs are much smaller compared to downward adjustment costs, both for wage and employment adjustment. Plants nearing exit bear a burden in terms of downward adjustment in wages and employment. The downward adjustment costs are also considerable even for continuing plants.

\section{Conclusion}

This paper investigated the dynamics of wages along the life-cycle of manufacturing plants. New plants start with lower wages compared to mature plants. Surviving plants' wages increase and catch up with those of mature plants. Wages in plants approaching exit fall, but not as steeply as they rise in entering plants. Wages constitute a lower fraction of young plants' revenue because their labor productivity, as measured by revenue per worker, grows faster than their wages. For plants approaching exit, wages do not fall as fast as labor productivity does, implying that a higher fraction of revenue must be dedicated to wage bill.

A model of plant-level dynamics with asymmetric wage adjustment costs was studied to account 
for the observed patterns. The model relates wage adjustment to adjustment in labor quality. The contribution of unobserved labor quality both to revenue and adjustment cost is inferred using the restrictions imposed by the dynamic optimization. The estimated parameters of the model reveal evidence of asymmetric adjustment costs in wages. The estimates remain economically significant when considered with employment adjustment cost. The estimation developed here can be applied to establishments in non-manufacturing industries, for which census data contain only revenue, payroll, and employment.

The cost of adjusting wages downward may increase the likelihood of exit and speed up the demise of failing plants. Further research can quantify the importance of these costs in exit. The model can be estimated separately for unionized and non-unionized plants to assess the role of unions in wage adjustment. An examination of persistence in plant-level profitability shocks and its implications on wage persistence is also desirable. Higher frequency data, such as annual, can be used to assess how adjustment costs change when shorter periods of adjustment are considered. Adjustments in other components of compensation, such as benefits, can also be introduced. It is also promising to investigate the differences in adjustment costs for wages of production vs. non-production workers. The empirical analysis suggests that the former is likely the main driver of the patterns observed in this paper. Finally, it is important to add adjustment costs in other key inputs, such as capital, to assess the relative magnitudes of different adjustment costs.

\section{References}

[1] Abraham, Arpad, and White, Kirk (2006) "The Dynamics of Plant Level Productivity in U.S. Manufacturing", Center for Economic Studies Working Paper No. 06-20.

[2] Altonji, Joseph G. and Devereux, Paul J. (1999) "Extent and Consequences of Downward Nominal Wage Rigidity." In Polachek, S. W. (ed.): Worker Well Being, Research in Labor Economics, 19, Elsevier.

[3] Bewley, Truman F. (1999) Why Wages Don't Fall During a Recession. Cambridge, MA: Harvard University Press.

[4] Blanchard, Oliver and Galí, Jordi (2007) "Real Wage Rigidities and the New Keynesian Model", Journal of Money, Credit and Banking, 39: 35-66.

[5] Charles Brown and Medoff, James L. (1989) "The Employer Size-Wage Effect", Journal of Political Economy, 97: 1027-59. 
[6] Charles Brown and Medoff, James L. (2003) "Firm Age and Wages", Journal of Labor Economics, 21: 677-698.

[7] Cooper, Russell and Willis, Jonathan (2011) "The Cost of Labor Adjustment: Inferences from the Gap", Review of Economic Dynamics, forthcoming.

[8] Cooper, Russell, Haltiwanger, John and Willis, Jonathan L. (2003) "Dynamics of Labor Demand: Evidenve from Plant-Level Observations and Aggregate Implications", Working paper.

[9] Cooper, Russell and Haltiwanger, John (2006) "On the Nature of Capital Adjustment Costs," Review of Economic Studies, 73: 611-34.

[10] Davis, Steven, Haltiwanger, John, and Schuh, Scott (1996) Job Creation and Destruction, Cambridge and London: MIT Press.

[11] Foster, Lucia, John, Haltiwanger, and Syverson, Chad (2008) "Reallocation, Firm Turnover, and Efficiency: Selection on Productivity or Profitability?", American Economic Review, 98: $394-425$.

[12] Fuss, Catherine and Wintr, Ladislav (2009) "Rigid Labour Compensation and Flexible Employment? Firm-level Evidence with Regard to Productivity for Belgium", Research series 200903-11, National Bank of Belgium.

[13] Gujarati, Damodar, and Dars, Lewis (1972) "Production and Nonproduction Workers in US Manufacturing Industries", Industrial and Labor Relations Review, 26: 660-669.

[14] Hall, Robert E. (2004) "Measuring Factor Adjustment Costs," Quarterly Journal of Economics, 119: 899-927.

[15] Hall, Robert E. (2005a), "Employment Fluctuations with Equilibrium Wage Stickiness", American Economic Review, 95: 50-65.

[16] Hall, Robert E. (2005b) "Employment Efficiency and Sticky Wages: Evidence from Flows in the Labor Market", Review of Economics and Statistics, 87: 397-407.

[17] Hansen. Lars P. and Singleton, Kenneth J. (1982) "Generalized Instrumental Variables Estimation of Nonlinear Rational Expectations Models", Econometrica, 50: 1269-1286. 
[18] Jovanovic, Boyan (1982) "Selection and the Evolution of the Industry", Econometrica, 50(3): 649-670.

[19] Kölling, Arnd, Schnabel, Claus, and Wagner, Joachim (2002) "Establishment Age and Wages: Evidence from German Linked Employer-Employee Data", Friedrich-Alexander University Erlangen-Nuremberg, Discussion Paper No. 13.

[20] Pakes, Ariel (1994) "The Estimation of Dynamic Structural Models: Problems and Prospects, Part II. Mixed Continuous-Discrete Control Models and Market Interactions", Chapter 5, pp. 171-259, of Advances in Econometrics: Proceedings of the 6th World Congress of the Econometric Society, edited by J.J. Laffont and C. Sims.

[21] Pfann, Gerard and Palm, Franz (1993) "Asymmetric Adjustment Costs in Non-linear Labour Demand Models for the Netherlands and U.K. Manufacturing Sectors" Review of Economic Studies, 60: 397-412.

[22] Stokey, Nancy L. and Lucas, Robert E. (1989) Recursive Methods in Economic Dynamics. Harvard University Press. 


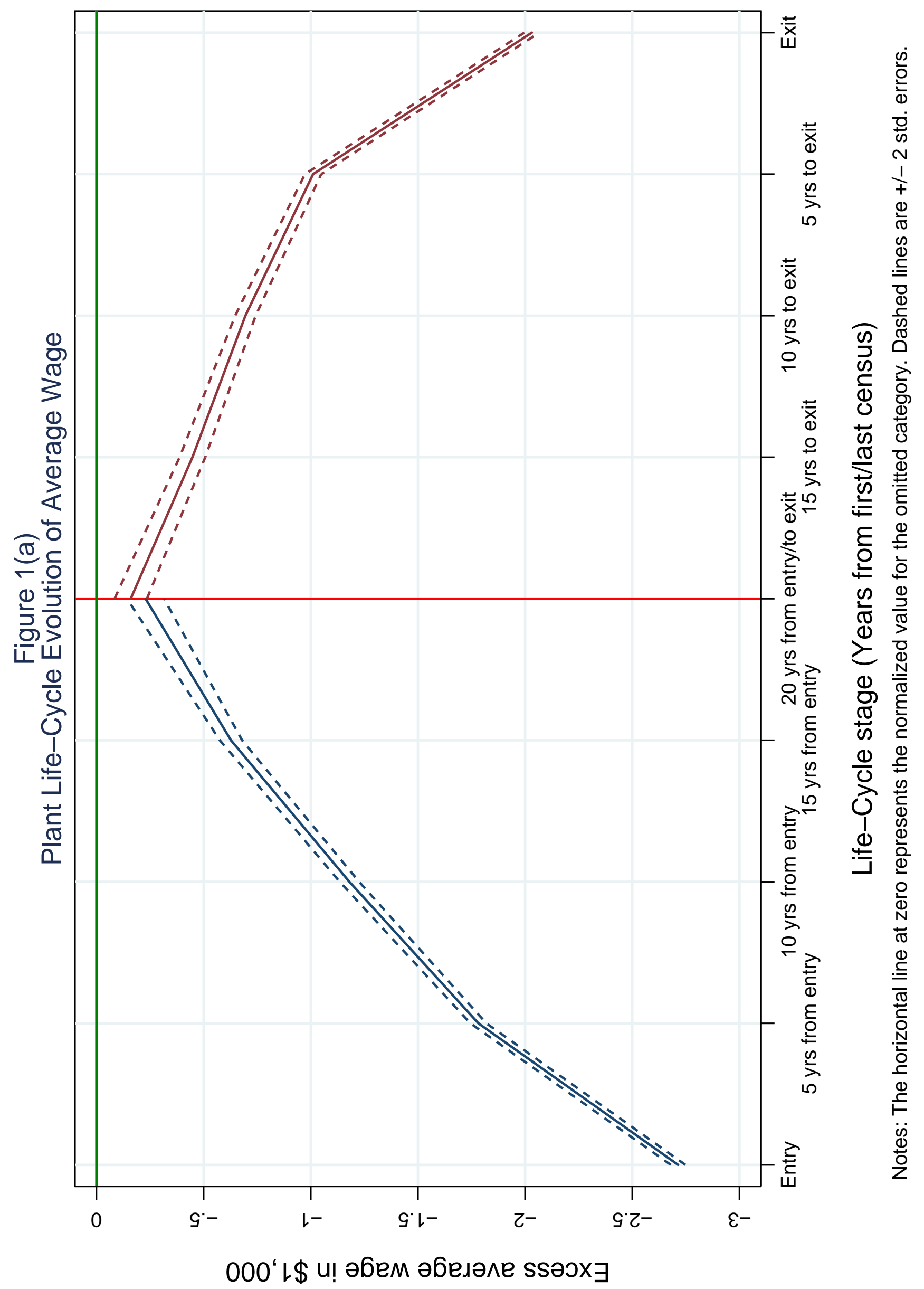




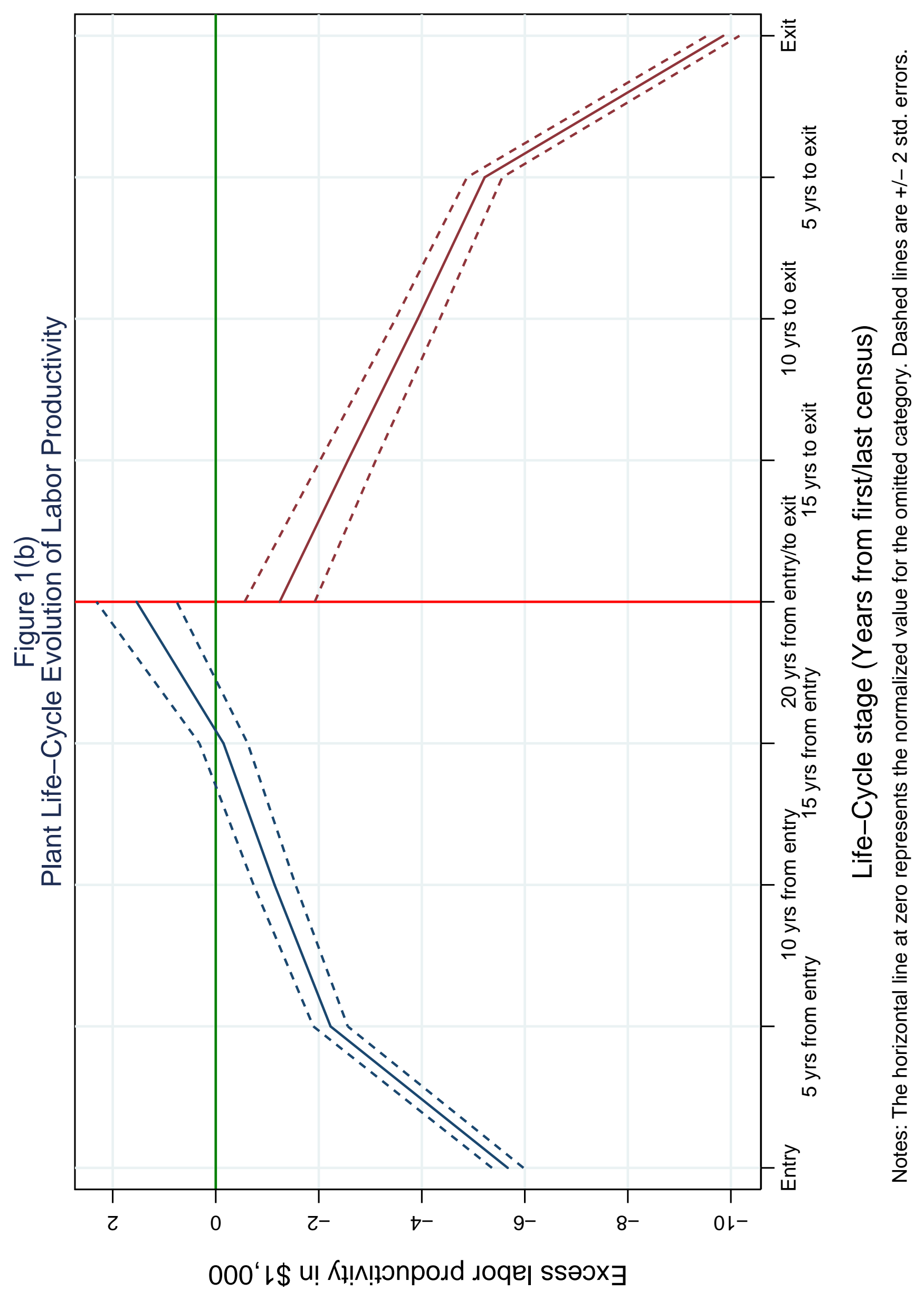




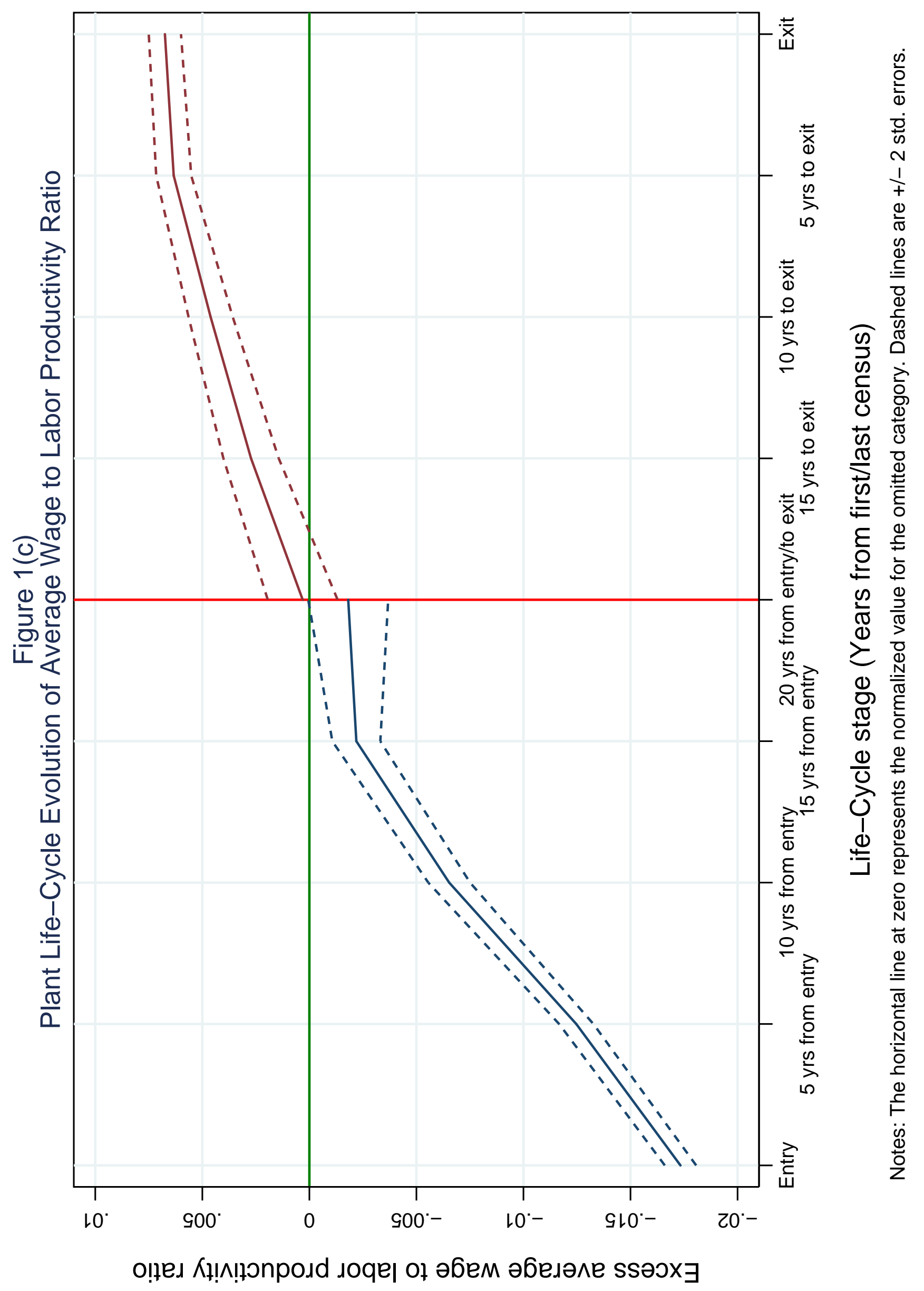




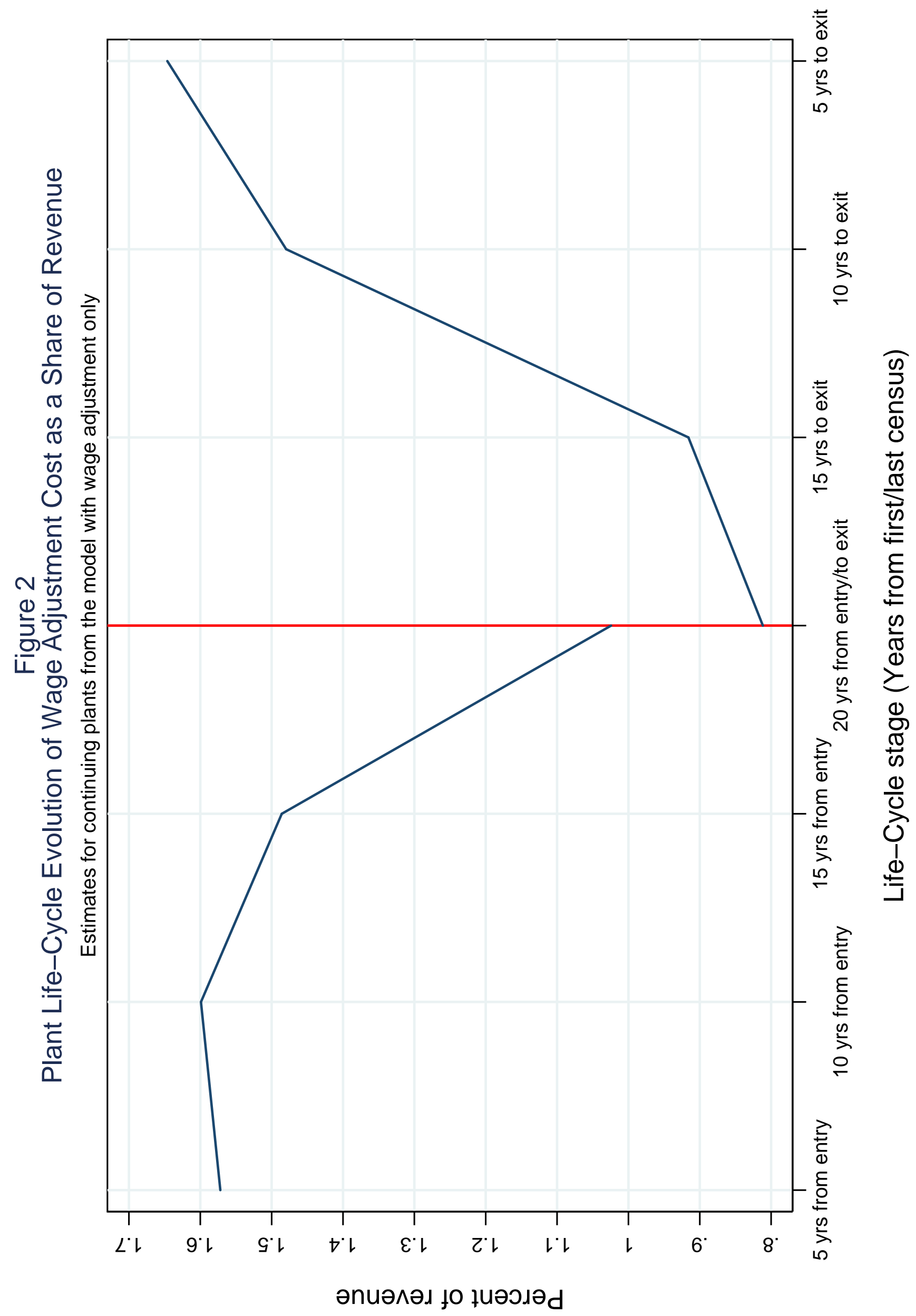




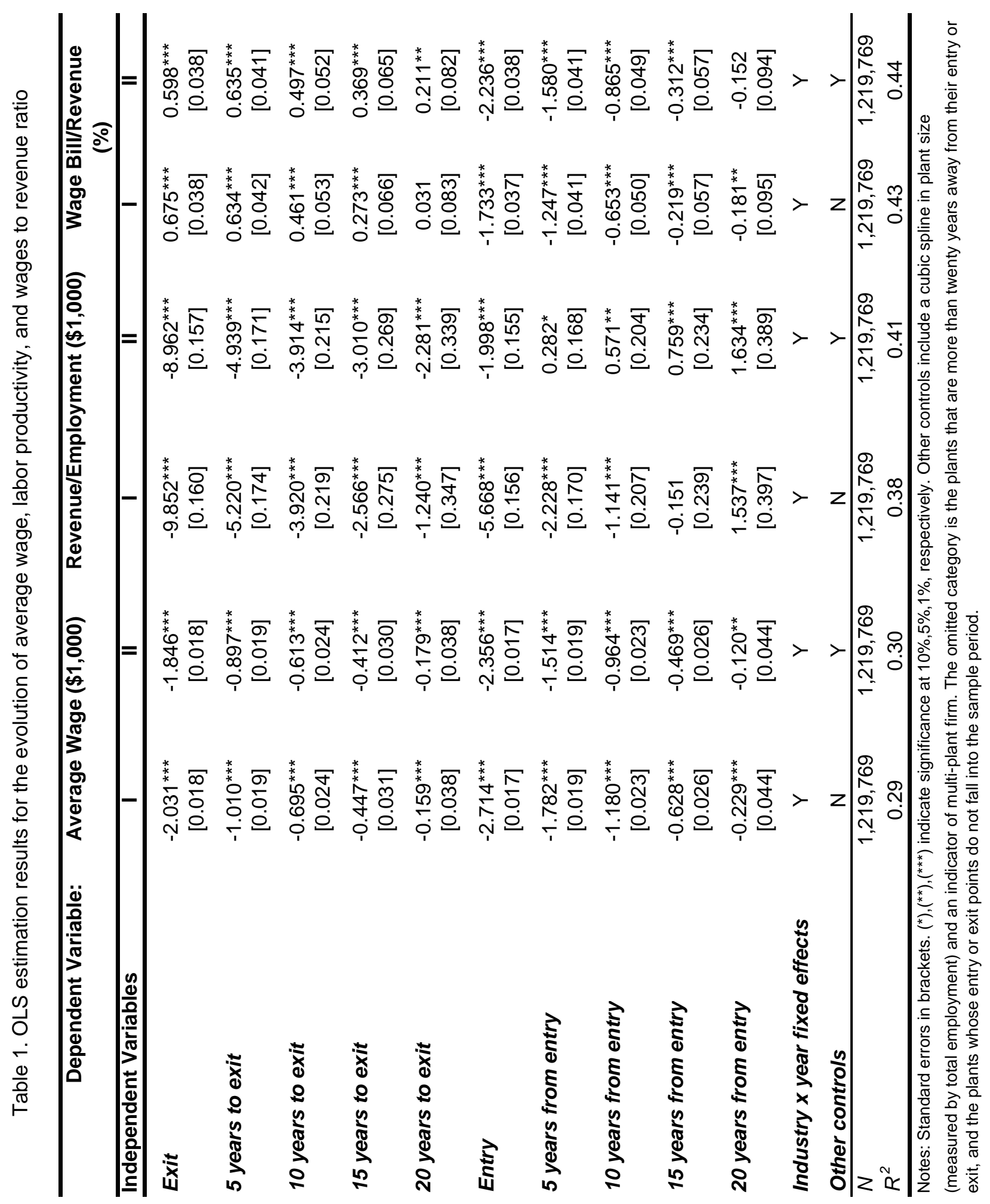




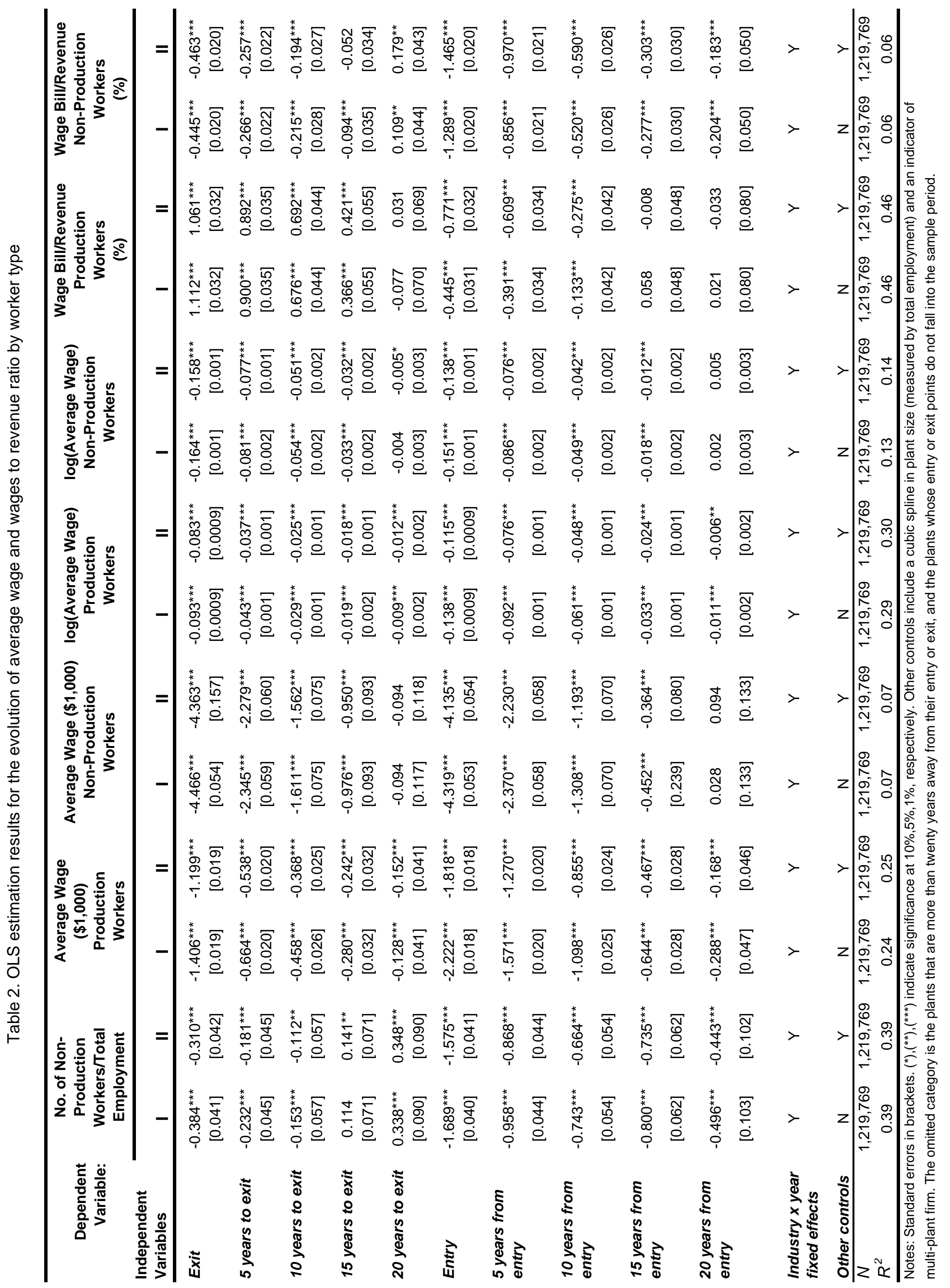


Table 3. Unconstrained GMM estimates for the model's parameters using all manufacturing plants

Revenue measure: Total value of shipments (deflated)

\begin{tabular}{|c|c|c|c|c|c|c|c|c|}
\hline & \multicolumn{4}{|c|}{$\begin{array}{c}\text { Adjustment costs } \\
\text { (conventional growth rate) }\end{array}$} & \multicolumn{4}{|c|}{$\begin{array}{c}\text { Adjustment cost } \\
\text { (alternative growth rate) }\end{array}$} \\
\hline & \multicolumn{2}{|c|}{$\begin{array}{c}\text { Wage } \\
\text { adjustment }\end{array}$} & \multicolumn{2}{|c|}{$\begin{array}{c}\text { Wage and } \\
\text { employment }\end{array}$} & \multicolumn{2}{|c|}{$\begin{array}{c}\text { Wage } \\
\text { adjustment }\end{array}$} & \multicolumn{2}{|c|}{$\begin{array}{c}\text { Wage and } \\
\text { employment }\end{array}$} \\
\hline Parameter & $\begin{array}{l}\text { Continuing } \\
\text { plants } \\
\text { (I) }\end{array}$ & $\begin{array}{c}\text { All } \\
\text { plants } \\
\text { (II) }\end{array}$ & $\begin{array}{l}\text { Continuing } \\
\text { plants } \\
\text { (III) }\end{array}$ & $\begin{array}{c}\text { All } \\
\text { plants } \\
\text { (IV) }\end{array}$ & $\begin{array}{l}\text { Continuing } \\
\text { plants } \\
\text { (I) }\end{array}$ & $\begin{array}{c}\text { All } \\
\text { plants } \\
\text { (II) }\end{array}$ & $\begin{array}{l}\text { Continuing } \\
\text { plants } \\
\text { (III) }\end{array}$ & $\begin{array}{c}\text { All } \\
\text { plants } \\
\text { (IV) }\end{array}$ \\
\hline$\alpha$ & $\begin{array}{c}0.12^{\star \star \star} \\
{[0.0005]}\end{array}$ & $\begin{array}{c}0.11^{\star * *} \\
{[0.0006]}\end{array}$ & $\begin{array}{l}0.12^{* * *} \\
{[0.002]}\end{array}$ & $\begin{array}{c}0.09^{* * *} \\
{[0.0006]}\end{array}$ & $\begin{array}{c}0.12^{\star \star \star} \\
{[0.0004]}\end{array}$ & $\begin{array}{c}0.13^{\star \star \star} \\
{[0.0004]}\end{array}$ & $\begin{array}{l}0.09^{\star \star *} \\
{[0.0005]}\end{array}$ & $\begin{array}{l}0.14^{\star \star *} \\
{[0.001]}\end{array}$ \\
\hline V & $\begin{array}{c}0.19^{* \star *} \\
{[0.0004]}\end{array}$ & $\begin{array}{c}0.18^{* \star *} \\
{[0.0005]}\end{array}$ & $\begin{array}{l}0.25^{\star \star \star} \\
{[0.002]}\end{array}$ & $\begin{array}{c}0.24^{\star \star *} \\
{[0.0007]}\end{array}$ & $\begin{array}{c}0.27^{* \star *} \\
{[0.0009]}\end{array}$ & $\begin{array}{l}0.42^{\star \star \star} \\
{[0.002]}\end{array}$ & $\begin{array}{l}0.08^{* \star *} \\
{[0.002]}\end{array}$ & $\begin{array}{l}0.13^{\star \star *} \\
{[0.002]}\end{array}$ \\
\hline$\lambda^{u}$ & $\begin{array}{c}2.89^{\star \star \star} \\
{[0.05]}\end{array}$ & $\begin{array}{l}-2.52^{\star \star \star} \\
{[0.04]}\end{array}$ & $\begin{array}{c}10.73^{* \star *} \\
{[0.41]}\end{array}$ & $\begin{array}{l}-0.98^{\star \star *} \\
{[0.01]}\end{array}$ & $\begin{array}{c}5.94^{\star \star \star} \\
{[0.11]}\end{array}$ & $\begin{array}{c}14.18^{\star \star *} \\
{[0.15]}\end{array}$ & $\begin{array}{c}-1.25^{\star \star \star} \\
{[0.03]}\end{array}$ & $\begin{array}{l}-2.71^{\star \star \star} \\
{[0.08]}\end{array}$ \\
\hline$\lambda^{D}$ & $\begin{array}{c}35.61 * \star \star \\
{[0.25]}\end{array}$ & $\begin{array}{c}63.10^{* \star *} \\
{[0.42]}\end{array}$ & $\begin{array}{c}20.81^{\star \star \star} \\
{[0.74]}\end{array}$ & $\begin{array}{c}56.48^{\star \star *} \\
{[0.33]}\end{array}$ & $\begin{array}{l}9.55^{\star \star *} \\
{[0.07]}\end{array}$ & $\begin{array}{l}6.30^{* \star *} \\
{[0.06]}\end{array}$ & $\begin{array}{c}10.10^{\star * \star} \\
{[0.12]}\end{array}$ & $\begin{array}{c}10.46^{\star \star \star} \\
{[0.33]}\end{array}$ \\
\hline$v^{u}$ & - & - & $\begin{array}{l}8.62^{\star \star *} \\
{[0.52]}\end{array}$ & $\begin{array}{c}-0.56^{\star \star \star} \\
{[0.03]}\end{array}$ & - & - & $\begin{array}{l}1.97^{\star \star \star} \\
{[0.42]}\end{array}$ & $\begin{array}{c}13.43^{\star * \star} \\
{[0.72]}\end{array}$ \\
\hline$v^{D}$ & - & - & $\begin{array}{c}23.17^{\star \star *} \\
{[4.82]}\end{array}$ & $\begin{array}{c}42.91^{* \star *} \\
{[1.03]}\end{array}$ & - & - & $\begin{array}{l}8.90^{* \star *} \\
{[0.12]}\end{array}$ & $\begin{array}{c}88.21 * * * \\
{[1.94]}\end{array}$ \\
\hline \multicolumn{9}{|c|}{ Revenue measure: Value added (deflated) } \\
\hline$\alpha$ & $\begin{array}{c}0.36^{\star \star \star} \\
{[0.0005]}\end{array}$ & $\begin{array}{c}0.39^{* \star *} \\
{[0.0008]}\end{array}$ & $\begin{array}{l}0.25^{\star \star \star} \\
{[0.003]}\end{array}$ & $\begin{array}{c}0.33^{\star * \star} \\
{[0.0007]}\end{array}$ & $\begin{array}{c}0.32^{\star * \star} \\
{[0.0002]}\end{array}$ & $\begin{array}{l}0.37^{\star \star *} \\
{[0.001]}\end{array}$ & $\begin{array}{c}0.27^{\star *} \\
{[0.001]}\end{array}$ & $\begin{array}{l}0.39 * \star * \\
{[0.003]}\end{array}$ \\
\hline$Y$ & $\begin{array}{l}0.47^{\star \star \star} \\
{[0.002]}\end{array}$ & $\begin{array}{l}0.44^{\star * *} \\
{[0.001]}\end{array}$ & $\begin{array}{l}0.37^{\star \star \star} \\
{[0.004]}\end{array}$ & $\begin{array}{l}0.39^{\star \star *} \\
{[0.002]}\end{array}$ & $\begin{array}{c}0.35^{\star \star \star} \\
{[0.0002]}\end{array}$ & $\begin{array}{l}0.27^{\star \star *} \\
{[0.001]}\end{array}$ & $\begin{array}{l}0.22^{* * *} \\
{[0.002]}\end{array}$ & $\begin{array}{l}0.42^{\star \star *} \\
{[0.002]}\end{array}$ \\
\hline$\lambda^{u}$ & $\begin{array}{c}1.39 * \star \star \\
{[0.04]}\end{array}$ & $\begin{array}{c}1.00^{\star \star \star} \\
{[0.02]}\end{array}$ & $\begin{array}{c}3.73^{\star \star \star} \\
{[0.24]}\end{array}$ & $\begin{array}{c}1.38^{\star \star \star} \\
{[0.04]}\end{array}$ & $\begin{array}{c}-3.44^{\star * \star} \\
{[0.08]}\end{array}$ & $\begin{array}{c}-3.05^{\star \star *} \\
{[0.06]}\end{array}$ & $\begin{array}{c}-1.04^{\star \star \star} \\
{[0.03]}\end{array}$ & $\begin{array}{c}-0.54^{\star \star \star} \\
{[0.05]}\end{array}$ \\
\hline$\lambda^{D}$ & $\begin{array}{c}15.63^{\star \star \star *} \\
{[0.17]}\end{array}$ & $\begin{array}{c}13.95^{\star \star \star} \\
{[0.20]}\end{array}$ & $\begin{array}{c}29.32^{\star \star \star} \\
{[0.47]}\end{array}$ & $\begin{array}{c}19.25^{\star \star \star} \\
{[0.21]}\end{array}$ & $\begin{array}{c}10.31^{\star * *} \\
{[0.06]}\end{array}$ & $\begin{array}{c}8.34^{\star \star \star} \\
{[0.06]}\end{array}$ & $\begin{array}{c}6.82^{\star \star \star} \\
{[0.08]}\end{array}$ & $\begin{array}{c}1.37^{\star \star \star} \\
{[0.22]}\end{array}$ \\
\hline$v^{u}$ & - & - & $\begin{array}{c}3.46^{\star \star \star} \\
{[0.28]}\end{array}$ & $\begin{array}{c}1.13^{\star \star \star} \\
{[0.04]}\end{array}$ & - & - & $\begin{array}{c}2.03^{\star \star \star} \\
{[0.32]}\end{array}$ & $\begin{array}{c}17.74^{\star \star \star} \\
{[0.79]}\end{array}$ \\
\hline$v^{D}$ & - & - & $\begin{array}{c}41.42^{\star * \star} \\
{[2.70]}\end{array}$ & $\begin{array}{c}47.60^{\star \star \star *} \\
{[0.72]}\end{array}$ & - & - & $\begin{array}{c}6.69^{\star \star \star} \\
{[0.09]}\end{array}$ & $\begin{array}{c}58.32^{\star \star \star} \\
{[2.20]}\end{array}$ \\
\hline $\bar{N}$ & 804,245 & 986,977 & 804,245 & 986,977 & 804,245 & 986,977 & 804,245 & 986,977 \\
\hline
\end{tabular}




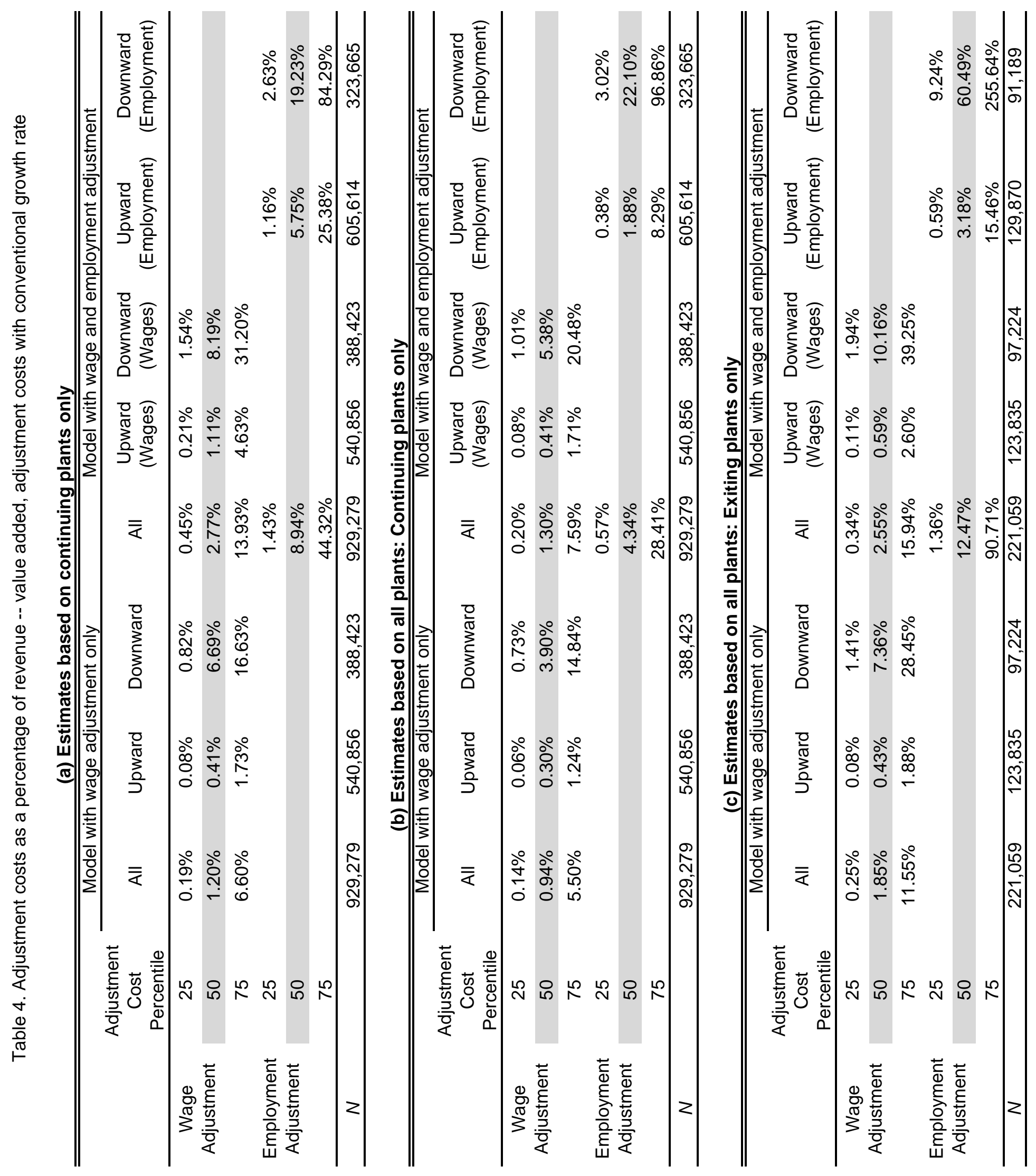




\section{Appendix}

\section{A Monotonicity of policy functions}

This appendix shows that under certain conditions the policy functions $L\left(\mathbf{s}_{t}\right)$ and $q\left(\mathbf{s}_{t}\right)$ are monotonically increasing in $\theta_{t}$, i.e. $\frac{d L\left(\mathbf{s}_{t}\right)}{d \theta_{t}}>0$ and $\frac{d q\left(\mathbf{s}_{t}\right)}{d \theta_{t}}>0$. Consider the case of wage adjustment cost with conventional growth rate. Other cases can be worked out similarly. Let $\lambda_{t} \equiv\left(I_{t}^{U} \frac{\lambda^{U}}{2}+I_{t}^{D} \frac{\lambda^{D}}{2}\right), K_{t+1} \equiv E\left[\lambda_{t+1}\left(\frac{w_{t+1} q_{t+1}-w_{t} q_{t}}{w_{t} q_{t}}\right)^{2}\right]$, and $M_{t+1} \equiv-E\left[\lambda_{t+1} \frac{w_{t+1}^{2} q_{t+1}^{2}-w_{t}^{2} q_{t}^{2}}{w_{t}^{2} q_{t}^{2}}\right]$. The first order conditions (4) and (6) can be written as

$$
\begin{gathered}
\alpha \theta_{t} L_{t}^{\alpha-1} q_{t}^{\gamma}=\left(1+\beta K_{t+1}\right) w_{t} q_{t}, \\
\gamma \theta_{t} L_{t}^{\alpha} q_{t}^{\gamma-1}=\left(1+2 \lambda_{t}\left(\frac{w_{t} q_{t}-w_{t-1} q_{t-1}}{w_{t-1} q_{t-1}}\right) \frac{L_{t-1}}{L_{t}}+\beta M_{t+1}\right) w_{t} L_{t} .
\end{gathered}
$$

Total differentiation of (19) and (20) with respect to $\theta_{t}$ results in the system

$$
\begin{aligned}
& A \frac{d L\left(\mathbf{s}_{t}\right)}{d \theta_{t}}+B \frac{d q\left(\mathbf{s}_{t}\right)}{d \theta_{t}}=E \\
& C \frac{d L\left(\mathbf{s}_{t}\right)}{d \theta_{t}}+D \frac{d q\left(\mathbf{s}_{t}\right)}{d \theta_{t}}=F
\end{aligned}
$$

which has the solution

$$
\begin{aligned}
\frac{d L\left(\mathbf{s}_{t}\right)}{d \theta_{t}} & =\frac{E D-B F}{A D-B C} \\
\frac{d q\left(\mathbf{s}_{t}\right)}{d \theta_{t}} & =\frac{A F-E C}{A D-B C}
\end{aligned}
$$

provided that $A D-B C \neq 0$. The coefficients of the system (21) are given by

$$
\begin{gathered}
A=\alpha(1-\alpha) \theta_{t} L_{t}^{\alpha-2} q_{t}^{\gamma-1}+w_{t} \beta \frac{\partial K_{t+1}}{\partial L_{t}}, \\
B=\alpha(1-\gamma) \theta_{t} L_{t}^{\alpha-1} q_{t}^{\gamma-2}+w_{t} \beta \frac{\partial K_{t+1}}{\partial q_{t}}, \\
E=\alpha L_{t}^{\alpha-1} q_{t}^{\gamma-1}-w_{t} \beta \frac{\partial K_{t+1}}{\partial \theta_{t}}, \\
C=\gamma(1-\alpha) \theta_{t} L_{t}^{\alpha-2} q_{t}^{\gamma-1}+w_{t} \beta\left(-2 \lambda_{t}\left(\frac{w_{t} q_{t}-w_{t-1} q_{t-1}}{w_{t-1} q_{t-1}}\right) \frac{L_{t-1}}{L_{t}^{2}}+\frac{\partial M_{t+1}}{\partial L_{t}}\right), \\
D=\gamma(1-\gamma) \theta_{t} L_{t}^{\alpha-1} q_{t}^{\gamma-2}+w_{t} \beta\left(2 \lambda_{t} \frac{w_{t}}{w_{t-1} q_{t-1}} \frac{L_{t-1}}{L_{t}}+\frac{\partial M_{t+1}}{\partial q_{t}}\right), \\
F=\gamma L_{t}^{\alpha-1} q_{t}^{\gamma-1}-w_{t} \beta \frac{\partial M_{t+1}}{\partial \theta_{t}} .
\end{gathered}
$$


For $L\left(\mathbf{s}_{t}\right)$ and $q\left(\mathbf{s}_{t}\right)$ to be strictly increasing in $\theta_{t}$, one of the following must hold

$$
\begin{aligned}
& A D-B C>0, A F-E C>0, E D-B F>0 \\
& A D-B C<0, A F-E C<0, E D-B F<0
\end{aligned}
$$

Thus, any restrictions on the model's parameters that guarantees (22) or (23) would be sufficient. Let's consider a set of sufficient conditions that leads to (22). Conditions that ensure (23) can also be derived similarly. Assume first that $\frac{\partial K_{t+1}}{\partial L_{t}}>0, \frac{\partial K_{t+1}}{\partial q_{t}}>0, \frac{\partial M_{t+1}}{\partial L_{t}}<0, \frac{\partial M_{t+1}}{\partial q_{t}}>0$. This assumption implies that period $t+1$ expected marginal cost of adjustment in average wage is strictly increasing in $q_{t}$ and $L_{t}$, except in the case of $M_{t+1}$ with respect to $L_{t}$. Assume also that $\frac{\partial K_{t+1}}{\partial \theta_{t}}<0$ and $\frac{\partial M_{t+1}}{\partial \theta_{t}}<0$, implying that the partial effect of an increase in $\theta_{t}$ on the expected marginal cost of adjustment in period $t+1$ is negative - this would be the case, for instance, if the stochastic process defined by $H\left(\theta_{t+1} \mid \theta_{t}\right)$ is such that a higher current period profitability shock $\theta_{t}$ implies a distribution of next period shock $\theta_{t+1}$ that assigns higher density to those shocks that render a smaller adjustment cost. In addition, assume that $C<0$, i.e. the net marginal effect on firm value of an increase in $L_{t}$ is strictly decreasing as $L_{t}$ increases. ${ }^{27}$ Under these assumptions, the coefficients of the system (21) have the following signs: $A, B, D, E, F>0$ and $C<0$. These signs imply that $A D-B C>0$ and $A F-E C>0$, ensuring that $\frac{d q\left(\mathbf{s}_{t}\right)}{d \theta_{t}}>0$. Finally, $E D-B F>0$ is needed for $\frac{d L\left(\mathbf{s}_{t}\right)}{d \theta_{t}}>0$. One can write

$$
\begin{aligned}
E D-B F= & w_{t} \beta\left[\left(2 \lambda_{t} \frac{w_{t}}{w_{t-1} q_{t-1}} \frac{L_{t-1}}{L_{t}}+\frac{\partial M_{t+1}}{\partial q_{t}}\right) E-\frac{\partial K_{t+1}}{\partial q_{t}} F\right] \\
& +\alpha(1-\gamma) \theta_{t} L_{t}^{\alpha-1} q_{t}^{\gamma-2} w_{t} \beta\left(\frac{\partial M_{t+1}}{\partial \theta_{t}}-\frac{\gamma}{\alpha} \frac{\partial K_{t+1}}{\partial \theta_{t}}\right)
\end{aligned}
$$

Now consider the terms on the r.h.s. of (24). The first term is positive, for instance, if $E>F$ and $\frac{\partial M_{t+1}}{\partial q_{t}}>\frac{\partial K_{t+1}}{\partial q_{t}}$. The second term is positive if $\frac{\frac{\partial K_{t+1}}{\partial \theta_{t}}}{\frac{\partial M_{t+1}}{\partial \theta_{t}}}>\frac{\alpha}{\gamma}$. Other sufficient conditions can be provided. Similarly, sufficient conditions can be stated for the case with both wage and employment adjustment, and for adjustment costs with alternative growth rates.

\section{B FOCs for adjustment costs with alternative growth rates}

\section{B.1 Adjustment cost for wages}

First order condition for $q_{t}$ :

\footnotetext{
${ }^{27}$ Because it was already assumed that $\frac{\partial M_{t+1}}{\partial L_{t}}<0$, one obtains $C<0$ if $\frac{\partial M_{t+1}}{\partial L_{t}}$ is sufficiently large in absolute value so that it overwhelms the positive terms in $C$.
} 


$$
\begin{aligned}
& \theta \gamma L_{t}^{\alpha} q_{t}^{\gamma-1}-w_{t} L_{t}-16\left(I_{t}^{U} \frac{\lambda^{U}}{2}+I_{t}^{D} \frac{\lambda^{D}}{2}\right) \frac{w_{t}}{\left(w_{t} q_{t}+w_{t-1} q_{t-1}\right)^{2}}\left(w_{t} q_{t}-w_{t-1} q_{t-1}\right) w_{t-1}^{2} q_{t-1}^{2} L_{t-1} \\
& +4 \beta\left(I_{t+1}^{U} \frac{\lambda^{U}}{2}+I_{t+1}^{D} \frac{\lambda^{D}}{2}\right) \frac{L_{t} w_{t}}{\left(w_{t} q_{t}+w_{t-1} q_{t-1}\right)^{2}}\left(w_{t+1} q_{t+1}-w_{t} q_{t}\right)\left(w_{t+1}^{2} q_{t+1}^{2}-w_{t}^{2} q_{t}^{2}-4 w_{t} q_{t} w_{t+1} q_{t+1}\right)=0
\end{aligned}
$$

First order condition for $L_{t}$ :

$$
\theta \alpha L_{t}^{\alpha-1} q_{t}^{\gamma-1}-w_{t} q_{t}-\beta\left(I_{t+1}^{U} \frac{\lambda^{U}}{2}+I_{t+1}^{D} \frac{\lambda^{D}}{2}\right)\left(2 \frac{w_{t+1} q_{t+1}-w_{t} q_{t}}{w_{t+1} q_{t+1}+w_{t} q_{t}}\right)^{2} w_{t} q_{t}=0
$$

\section{B.2 Adjustment cost for wages and employment}

First order condition for $q_{t}$ :

$$
\begin{aligned}
& \theta \gamma L_{t}^{\alpha} q_{t}^{\gamma-1}-w_{t} L_{t}-16\left(I_{t}^{U} \frac{\lambda^{U}}{2}+I_{t}^{D} \frac{\lambda^{D}}{2}\right) \frac{w_{t}}{\left(w_{t} q_{t}+w_{t-1} q_{t-1}\right)^{2}}\left(w_{t} q_{t}-w_{t-1} q_{t-1}\right) w_{t-1}^{2} q_{t-1}^{2} L_{t-1} \\
& +4 \beta\left(I_{t+1}^{U} \frac{\lambda^{U}}{2}+I_{t+1}^{D} \frac{\lambda^{D}}{2}\right) \frac{L_{t} w_{t}}{\left(w_{t} q_{t}+w_{t-1} q_{t-1}\right)^{2}}\left(w_{t+1} q_{t+1}-w_{t} q_{t}\right)\left(w_{t+1}^{2} q_{t+1}^{2}-w_{t}^{2} q_{t}^{2}-4 w_{t} q_{t} w_{t+1} q_{t+1}\right)=0
\end{aligned}
$$

First order condition for $L_{t}$ :

$$
\begin{aligned}
& \theta \alpha L_{t}^{\alpha-1} q_{t}^{\gamma-1}-w_{t} q_{t}-16\left(J_{t}^{U} \frac{\lambda^{U}}{2}+J_{t}^{D} \frac{\lambda^{D}}{2}\right) L_{t-1}^{2} \frac{L_{t}-L_{t-1}}{\left(L_{t}+L_{t-1}\right)^{2}} \\
& -\beta\left[\left(I_{t+1}^{U} \frac{\lambda^{U}}{2}+I_{t+1}^{D} \frac{\lambda^{D}}{2}\right)\left(2 \frac{w_{t+1} q_{t+1}-w_{t} q_{t}}{w_{t+1} q_{t+1}+w_{t} q_{t}}\right)^{2} w_{t} q_{t}+\frac{4\left(L_{t}-L_{t+1}\right)\left(4 L_{t} L_{t+1}+L_{t}^{2}-L_{t+1}^{2}\right)}{\left(L_{t}+L_{t+1}\right)^{2}}\left(J_{t+1}^{U} \frac{v^{U}}{2}+J_{t+1}^{D} \frac{v^{D}}{2}\right)\right]=0
\end{aligned}
$$




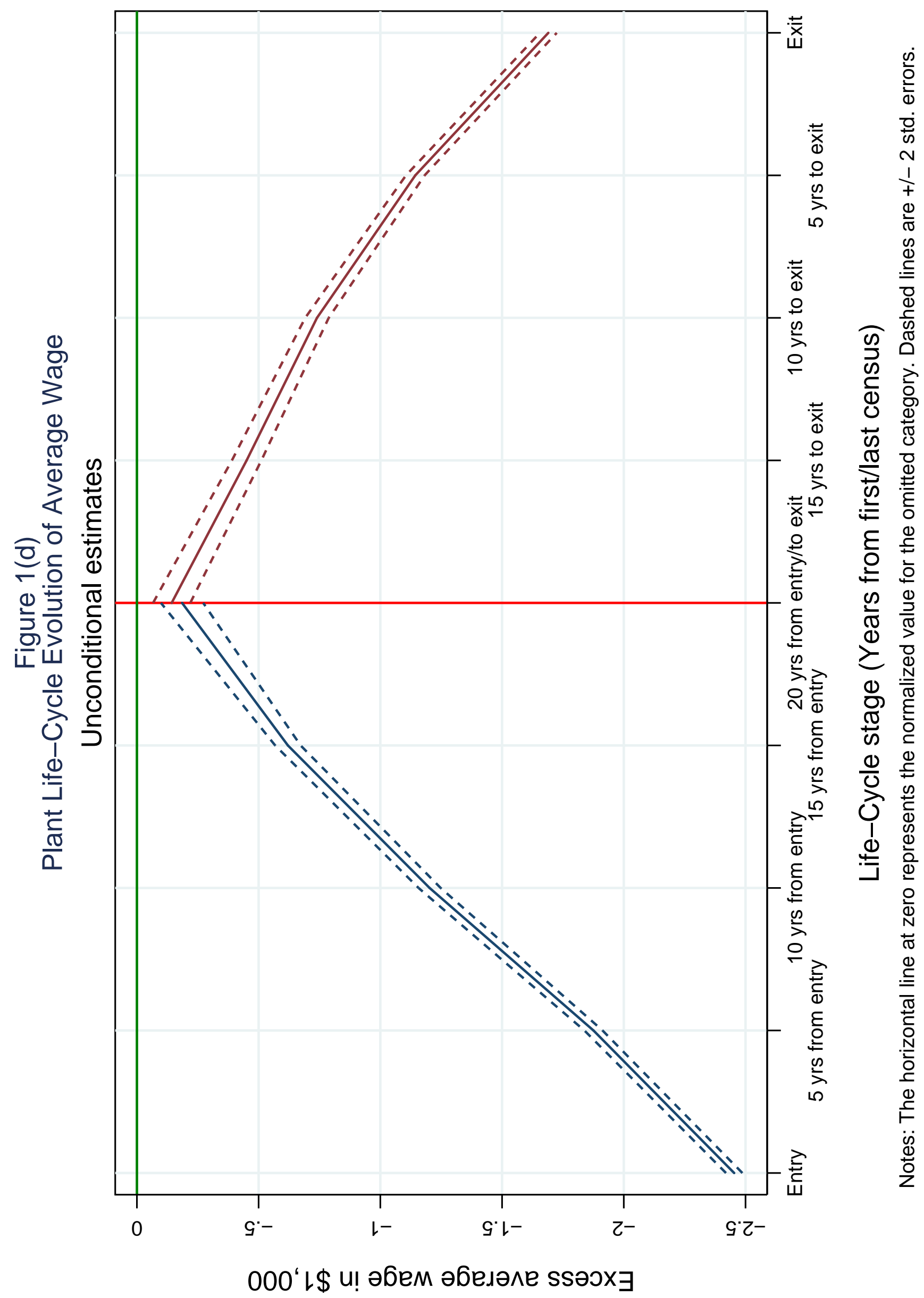




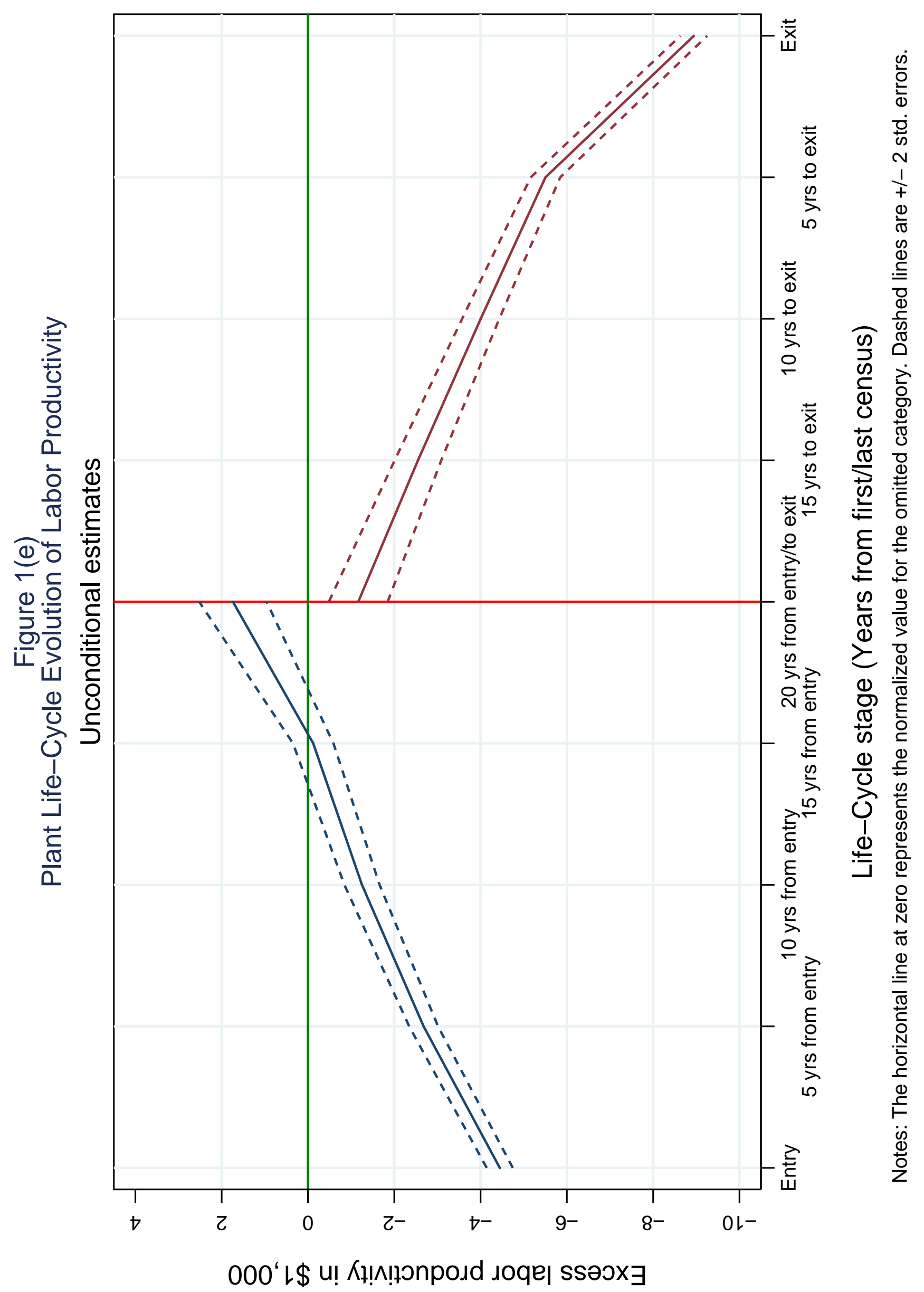




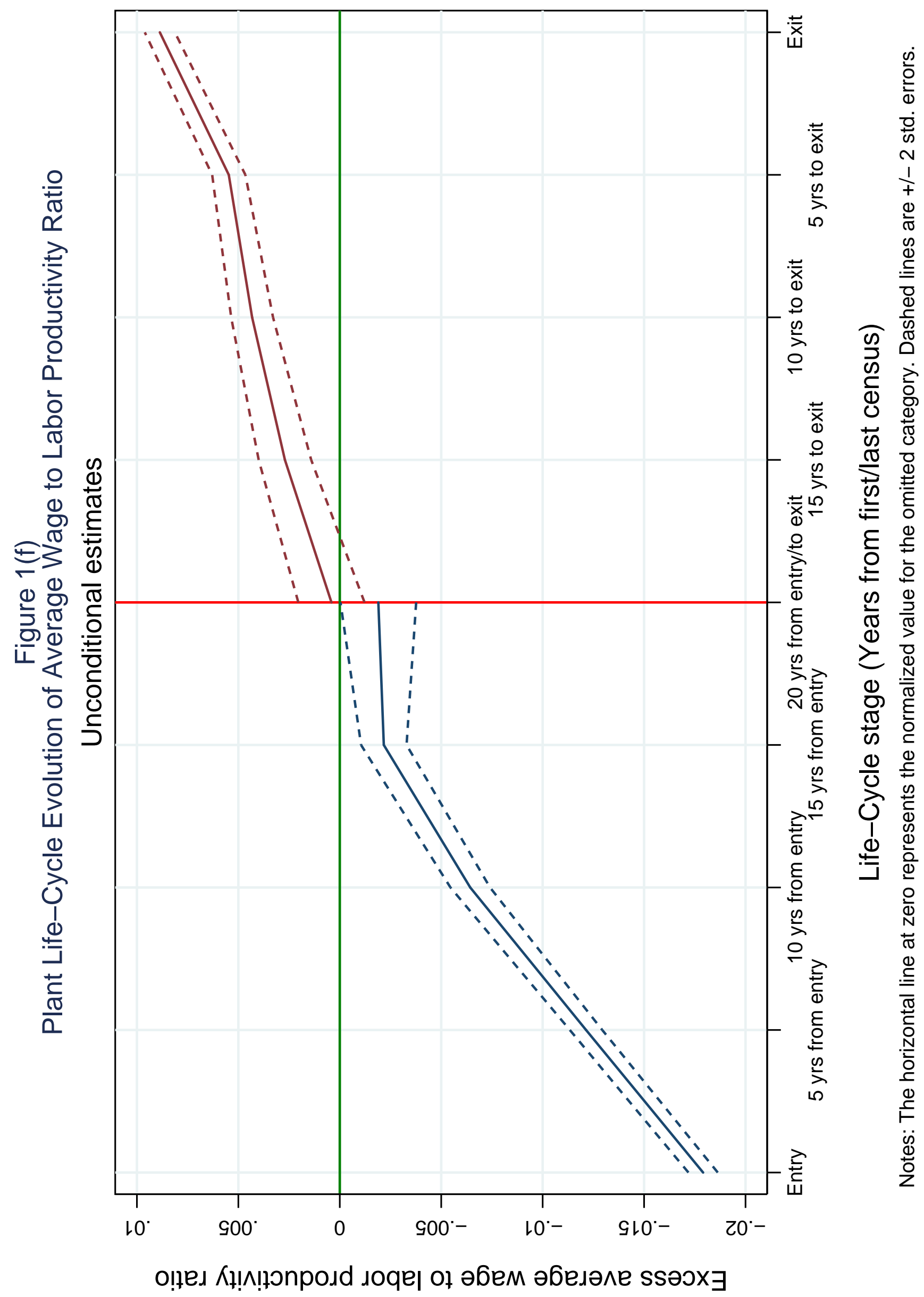


Table 3A. Constrained GMM estimates for the model's parameters using all manufacturing plants

Revenue measure: Total value of shipments (deflated)

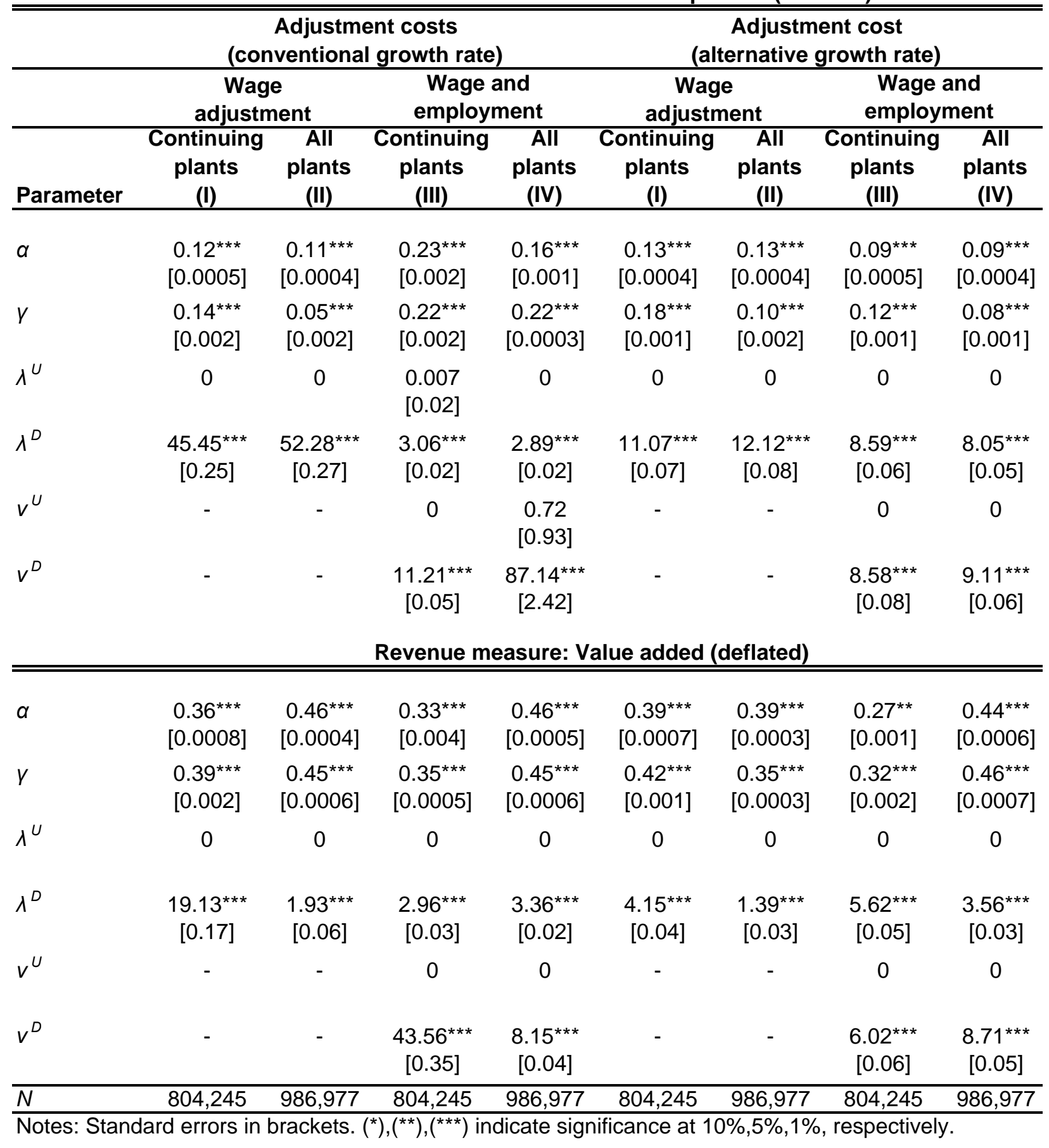

